\title{
New insights into the protein aggregation pathology in myotilinopathy by combined proteomic and immunolocalization analyses
}

A. Maerkens ${ }^{1,2}$, M. Olivé ${ }^{3}$, A. Schreiner ${ }^{1}$, S. Feldkirchner ${ }^{4}$, J. Schessl ${ }^{4}$, J. Uszkoreit ${ }^{2}$, K. Barkovits $^{2}$, A. K. Güttsches ${ }^{1}$, V. Theis ${ }^{2,5}$, M. Eisenacher ${ }^{2}$, M. Tegenthoff ${ }^{1}$, L. G. Goldfarb ${ }^{6}$, R. Schröder ${ }^{7}$, B. Schoser ${ }^{4}$, P. F. M. van der Ven ${ }^{8}$,

D. O. Fürst ${ }^{8}$, M. Vorgerd ${ }^{1}$, K. Marcus $^{2+}$ and R. A. Kley ${ }^{1 *+}$

\begin{abstract}
Introduction: Myofibrillar myopathies are characterized by progressive muscle weakness and impressive abnormal protein aggregation in muscle fibers. In about $10 \%$ of patients, the disease is caused by mutations in the MYOT gene encoding myotilin. The aim of our study was to decipher the composition of protein deposits in myotilinopathy to get new information about aggregate pathology.

Results: Skeletal muscle samples from 15 myotilinopathy patients were included in the study. Aggregate and control samples were collected from muscle sections by laser microdissection and subsequently analyzed by a highly sensitive proteomic approach that enables a relative protein quantification. In total 1002 different proteins were detected. Seventy-six proteins showed a significant over-representation in aggregate samples including 66 newly identified aggregate proteins. Z-disc-associated proteins were the most abundant aggregate components, followed by sarcolemmal and extracellular matrix proteins, proteins involved in protein quality control and degradation, and proteins with a function in actin dynamics or cytoskeletal transport. Forty over-represented proteins were evaluated by immunolocalization studies. These analyses validated our mass spectrometric data and revealed different regions of protein accumulation in abnormal muscle fibers. Comparison of data from our proteomic analysis in myotilinopathy with findings in other myofibrillar myopathy subtypes indicates a characteristic basic pattern of aggregate composition and resulted in identification of a highly sensitive and specific diagnostic marker for myotilinopathy.

Conclusions: Our findings i) indicate that main protein components of aggregates belong to a network of interacting proteins, ii) provide new insights into the complex regulation of protein degradation in myotilinopathy that may be relevant for new treatment strategies, iii) imply a combination of a toxic gain-of-function leading to myotilin-positive protein aggregates and a loss-of-function caused by a shift in subcellular distribution with a deficiency of myotilin at Z-discs that impairs the integrity of myofibrils, and iv) demonstrate that proteomic analysis can be helpful in differential diagnosis of protein aggregate myopathies.
\end{abstract}

Keywords: Myotilinopathy, Myofibrillar myopathy, Protein aggregation, Laser microdissection, Mass spectrometry, Immunolocalization study

\footnotetext{
*Correspondence: rudolf.kley@rub.de

${ }^{\dagger}$ Equal contributors

'Department of Neurology, Heimer Institute for Muscle Research, University

Hospital Bergmannsheil, Ruhr-University Bochum, Buerkle-de-la-Camp-Platz 1,

D-44789 Bochum, Germany

Full list of author information is available at the end of the article
} 


\section{Introduction}

Myofibrillar myopathies (MFM) comprise a genetically and clinically heterogeneous group of inherited muscle disorders characterized by focal disintegration of myofibrils predominantly at the Z-discs and by sarcoplasmic protein aggregation in muscle fibers [1-3]. In approximately $10 \%$ of MFM patients, the disease is caused by mutations in the MYOT (synonym TTID) gene on chromosome $5 \mathrm{q} 31[4,5]$. This gene encodes the $57 \mathrm{kDa}$ Z-disc protein myotilin [6], an actin-cross-linking protein that plays an important role in sarcomere assembly and stabilization of myofibrillar Z-discs [6, 7]. Myotilin consists of a unique serine-rich amino terminal region, two Ig-like domains necessary for the formation of antiparallel myotilin dimers, and a short carboxy terminal tail $[6,7]$. It directly binds filamin C [8], $\alpha$-actinin [6, 7], FATZ-1 [9] and ZASP [10].

MFM associated with myotilin mutations, hereafter referred to as myotilinopathy, usually manifests between the 5 th and 8th decade of life with progressive muscle weakness most often starting at distal lower limbs $[4,5,11]$. Peripheral neuropathy, cardiomyopathy and respiratory failure have been described in a subset of patients but are not constant features of myotilinopathy $[4,11,12]$.

Histological characteristics of myotilinopathy include variation of fiber size, fibro-fatty tissue proliferation, type I fiber predominance, core-like lesions, rimmed vacuoles and non-rimmed vacuolated areas. Indeed, the most prominent myopathological features in modified trichrome stain are pleomorphic protein deposits in so-called abnormal fibers described as hyaline dense inclusions, non-hyaline amorphous inclusions, spheroid inclusion bodies or nemaline-like bodies $[11,13]$. Immunohistochemical studies identified an accumulation of several proteins in these deposits, including myotilin and other Z-disc proteins, ectopically expressed sarcolemmal proteins and proteins involved in protein degradation pathways [4, 5, 11, 14-16]. However, since these immunolocalization studies were hypothesisdriven and restricted to pre-selected proteins, the precise constitution of deposits and the mechanisms of protein aggregation are largely unknown.

We established a highly sensitive proteomic approach to decipher the composition of MFM aggregates selectively collected from abnormal fibers by laser microdissection $[17,18]$. We already applied this method in filaminopathy and desminopathy $[17,18]$, two MFM subtypes caused by mutations in FLNC and DES, respectively. Analysis of samples from six filaminopathy [17] and five desminopathy [18] patients revealed several novel aggregate components and provided new insights into the pathomechanisms of these diseases. In addition, subtype specific proteomic profiles were detected that can be helpful in differential diagnosis of protein aggregate myopathies.
We here present a proteomic study in myotilinopathy, including samples from 15 patients harboring four different MYOT mutations. We used our established combined laser microdissection and mass spectrometry approach to identify new disease-relevant proteins that accumulate in abnormal fibers. Extensive immunofluorescence studies were performed to validate our proteomic findings and to get a deeper insight into the subcellular distribution of proteins. Furthermore, we compared the results with our previous findings in filaminopathy and desminopathy in order to identify specific proteomic markers for myotilinopathy.

\section{Materials and methods \\ Patients}

Skeletal muscle samples from 15 myotilinopathy patients with a histological phenotype typical of MFM and with known pathogenic mutations in exon 2 of MYOT were included in this study. Two patients carried a p.Lys36Glu mutation [11], one patient a p.Ser55Phe mutation $[4,11]$, six patients a p.Ser60Cys mutation $[4,11]$, and six patients a p.Ser60Phe mutation [4, 11]. More detailed data of patients and muscle samples are presented in Table 1.

\section{Proteomic analysis}

A combined laser microdissection and label free mass spectrometry approach (see workflow in Fig. 1) was applied as described by us before $[17,18]$ with modifications.

\section{Laser Microdissection and sample processing}

Frozen sections $(10 \mu \mathrm{m})$ of skeletal muscle samples (see above) were used for sample collection by laser microdissection. Immunofluorescence staining with a

Table 1 Overview of myotilinopathy patients included in this study

\begin{tabular}{lllll}
\hline ID & Gender & Age at biopsy [years] & Muscle & MYOT mutation \\
\hline 1 & Male & 78 & biceps brachii & p.Ser60Phe \\
2 & Female & 64 & gastrocnemius & p.Ser60Cys \\
3 & Female & 74 & vastus lateralis & p.Ser55Phe \\
4 & Female & 82 & tibialis anterior & p.Ser60Phe \\
5 & Male & 80 & vastus lateralis & p.Lys36Glu \\
6 & Female & 81 & vastus lateralis & p.Lys36Glu \\
7 & Male & 78 & biceps brachii & p.Ser60Phe \\
8 & Male & 52 & vastus lateralis & p.Ser60Cys \\
9 & Male & 72 & gastrocnemicus & p.Ser60Cys \\
10 & Male & 77 & tibialis anterior & p.Ser60Cys \\
11 & Female & 85 & vastus lateralis & p.Ser60Cys \\
12 & Male & 65 & vastus lateralis & p.Ser60Phe \\
13 & Female & 69 & deltoideus & p.Ser60Cys \\
14 & Male & 71 & tibialis anterior & p.Ser60Phe \\
15 & Male & 80 & vastus lateralis & p.Ser60Phe \\
\hline
\end{tabular}




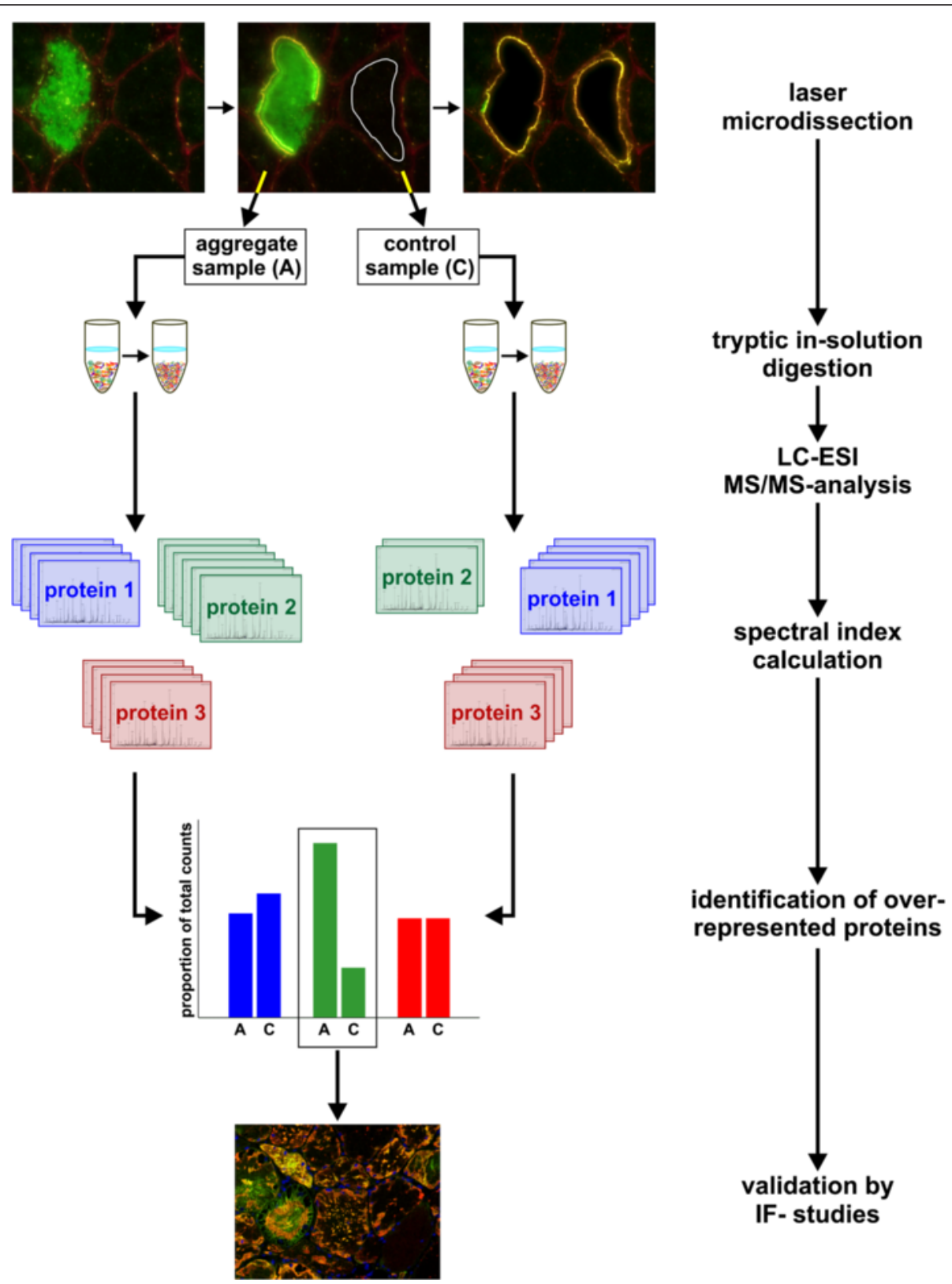

Fig. 1 Workflow of our combined laser microdissection and label-free proteomic approach. Frozen skeletal muscle sections from myotilinopathy patients were immunostained using a primary antibody directed against myotilin in order to detect protein aggregation in affected muscle fibers. Protein aggregates ("aggregate samples") and aggregate-free areas in fibers with a normal appearance ("control samples") were collected from the same section by laser microdissection (LMD). After tryptic in-solution digestion of extracted proteins, protein identification was performed by LC-ESI-MS/MS-analysis. Proteins with an over-representation in aggregate samples compared to control samples were identified by label-free relative quantification (spectral index calculation). For validation of proteomic data, serial cryosections of muscle samples from myotilinopathy patients were immunostained with primary antibodies directed against selected proteins identified as over-represented in aggregate samples

primary antibody directed against myotilin (Additional file 1: Table S1) to detect protein aggregation in abnormal muscle fibers was performed as described [18]. A total area of $250,000 \mu \mathrm{m}^{2}$ of protein aggregates and surrounding sarcoplasm (hereinafter referred as "aggregate samples") and the same area of sarcoplasm of aggregatefree muscle fibers from the same sections (intraindividual "control samples") were collected into tubes with $40 \mu \mathrm{l}$ formic acid (FA, 98-100 \%) by laser microdissection (LMD 6500, Leica Microsystems, Wetzlar, Germany). After incubation for $30 \mathrm{~min}$ at room temperature and sonification $(35 \mathrm{kHz}$ ) for $5 \mathrm{~min}$ (RK31, BANDELIN electronic, Berlin, Germany) the samples were centrifuged for $10 \mathrm{~min}\left(12,000 \mathrm{~g}, 4{ }^{\circ} \mathrm{C}\right)$ and frozen at $-80{ }^{\circ} \mathrm{C}$. 
Table 2 Proteins identified as over-represented in aggregate samples in myotilinopathy

\begin{tabular}{|c|c|c|c|c|}
\hline \multirow[b]{2}{*}{ Protein } & \multicolumn{2}{|c|}{ Mean proportion [\%] ${ }^{a}$} & \multirow[b]{2}{*}{ Ratio } & \multirow[b]{2}{*}{$p$ value } \\
\hline & Aggregates & Control & & \\
\hline Desmin & 52.09 & 14.36 & 3.6 & $6.75 \times 10^{-6}$ \\
\hline Filamin C & 31.82 & 17.86 & 1.8 & $6.69 \times 10^{-6}$ \\
\hline Myotilin & 24.05 & 4.51 & 5.3 & $2.91 \times 10^{-8}$ \\
\hline Xin actin-binding repeat-containing protein 2 (XIRP2) & 21.75 & 0.10 & 214.8 & $7.66 \times 10^{-6}$ \\
\hline Nebulin-related-anchoring protein (N-RAP) & 18.19 & 0.57 & 31.7 & $7.31 \times 10^{-7}$ \\
\hline Plectin & 14.27 & 6.75 & 2.1 & 0.0003 \\
\hline Collagen alpha-3(VI) chain & 11.22 & 1.99 & 5.6 & $1.88 \times 10^{-5}$ \\
\hline Obscurin & 8.49 & 4.68 & 1.8 & 0.0020 \\
\hline Xin actin-binding repeat-containing protein 1 (Xin) & 7.17 & 0.67 & 10.7 & $1.88 \times 10^{-7}$ \\
\hline Alpha-crystallin B chain (aB-crystallin) & 6.50 & 1.08 & 6.0 & $1.03 \times 10^{-5}$ \\
\hline Nestin & 5.14 & 0.11 & 47.3 & $7.62 \times 10^{-6}$ \\
\hline Myosin-3 & 4.16 & 1.13 & 3.7 & 0.0043 \\
\hline Histone $\mathrm{H} 4$ & 3.87 & 1.23 & 3.1 & $3.08 \times 10^{-5}$ \\
\hline Collagen alpha-1(VI) chain & 3.73 & 0.80 & 4.7 & 0.0005 \\
\hline Myosin-binding protein $\mathrm{H}$ (MYBPH) & 3.19 & 0.51 & 6.3 & 0.0029 \\
\hline Fibrillin-1 & 2.90 & 0.58 & 5.0 & 0.0230 \\
\hline Dysferlin & 2.71 & 0.33 & 8.2 & $2.91 \times 10^{-6}$ \\
\hline Prelamin-A/C & 2.67 & 0.56 & 4.8 & $2.44 \times 10^{-5}$ \\
\hline PDZ and LIM domain protein 3 & 2.56 & 1.26 & 2.0 & 0.0029 \\
\hline Collagen alpha-2(VI) chain & 2.41 & 0.52 & 4.6 & 0.0004 \\
\hline Heat shock cognate $71 \mathrm{kDa}$ protein (HSPA8/Hsc70) & 2.40 & 0.99 & 2.4 & 0.0001 \\
\hline Collagen alpha-1(I) chain & 2.05 & 0.53 & 3.8 & 0.0475 \\
\hline Sequestosome-1 (p62) & 1.75 & 0.03 & 52.0 & 0.0001 \\
\hline Collagen alpha-2(I) chain & 1.62 & 0.58 & 2.8 & 0.0080 \\
\hline Tubulin alpha- $4 \mathrm{~A}$ chain & 1.51 & 0.79 & 1.9 & 0.0074 \\
\hline Heat shock protein beta-1 (HSPB1/Hsp27) & 1.40 & 0.44 & 3.2 & 0.0173 \\
\hline Basement membrane-specific heparan sulfate proteoglycan core protein (Perlecan) & 1.25 & 0.26 & 4.8 & 0.0077 \\
\hline Laminin subunit gamma-1 & 1.25 & 0.06 & 20.6 & 0.0001 \\
\hline NADH-cytochrome b5 reductase 1 & 1.13 & 0.69 & 1.6 & 0.0385 \\
\hline Laminin subunit beta-2 & 1.07 & 0.23 & 4.6 & 0.0110 \\
\hline Kelch-like protein 40 & 1.07 & 0.49 & 2.2 & 0.0207 \\
\hline Dystrophin & 1.04 & 0.12 & 8.6 & 0.0004 \\
\hline Collagen alpha-2(IV) chain & 0.97 & 0.31 & 3.1 & 0.0016 \\
\hline Heat shock $70 \mathrm{kDa}$ protein $1 \mathrm{~A} / 1 \mathrm{~B}$ & 0.90 & 0.42 & 2.2 & 0.0030 \\
\hline ATP synthase F(0) complex subunit B1, mitochondrial & 0.90 & 0.48 & 1.9 & 0.0121 \\
\hline Tubulin beta chain & 0.79 & 0.29 & 2.8 & 0.0016 \\
\hline Decorin & 0.79 & 0.08 & 9.7 & 0.0230 \\
\hline BAG family molecular chaperone regulator 3 (BAG3) & 0.71 & 0.14 & 5.2 & 0.0007 \\
\hline Collagen alpha-1(III) chain & 0.69 & 0.19 & 3.6 & 0.0348 \\
\hline Microsomal glutathione S-transferase 3 (MGST3) & 0.68 & 0.27 & 2.5 & 0.0365 \\
\hline Synaptophysin-like protein 2 & 0.57 & 0.19 & 2.9 & 0.0087 \\
\hline Myosin-14 & 0.52 & n.d. & n.a. & 0.0203 \\
\hline Muscle-related coiled-coil protein (MURC) & 0.49 & n.d. & n.a. & 0.0491 \\
\hline
\end{tabular}


Table 2 Proteins identified as over-represented in aggregate samples in myotilinopathy (Continued)

\begin{tabular}{|c|c|c|c|c|}
\hline NADH-cytochrome b5 reductase 3 & 0.45 & 0.07 & 6.8 & 0.0010 \\
\hline Myopalladin & 0.44 & n.d. & n.a. & 0.0027 \\
\hline Microtubule-associated protein 4 (MAP4) & 0.43 & 0.02 & 25.9 & 0.0110 \\
\hline Sarcolemmal membrane-associated protein & 0.40 & 0.10 & 4.0 & 0.0131 \\
\hline Protein kinase $C$ and casein kinase substrate in neurons protein 3 (PACSIN 3) & 0.40 & 0.02 & 20.2 & 0.0041 \\
\hline Next to BRCA1 gene 1 protein (NBR1) & 0.37 & n.d. & n.a. & 0.0057 \\
\hline Supervillin & 0.31 & 0.09 & 3.3 & 0.0315 \\
\hline 14-3-3 protein gamma & 0.30 & 0.08 & 3.8 & 0.0134 \\
\hline Tropomodulin-1 & 0.29 & 0.02 & 15.0 & 0.0019 \\
\hline Syncoilin & 0.28 & n.d. & n.a. & 0.0021 \\
\hline Voltage-dependent calcium channel subunit alpha-2/delta-1 & 0.28 & 0.02 & 16.7 & 0.0084 \\
\hline Histone H1.0 & 0.26 & n.d. & n.a. & 0.0016 \\
\hline Signal recognition particle subunit SRP68 & 0.26 & 0.04 & 6.0 & 0.0258 \\
\hline Unconventional myosin-XVIIIa & 0.26 & n.d. & n.a. & 0.0043 \\
\hline Tubulin beta-4B chain & 0.24 & 0.04 & 5.8 & 0.0013 \\
\hline Xaa-Pro aminopeptidase 1 & 0.23 & n.d. & n.a. & 0.0018 \\
\hline Myeloid leukemia factor 2 & 0.22 & n.d. & n.a. & 0.0021 \\
\hline Myosin-10 & 0.17 & n.d. & n.a. & 0.0455 \\
\hline Elastin & 0.16 & n.d. & n.a. & 0.0465 \\
\hline Protein NipSnap homolog 2 & 0.16 & n.d. & n.a. & 0.0254 \\
\hline $60 S$ ribosomal protein L12 & 0.16 & 0.03 & 6.3 & 0.0355 \\
\hline Heat shock protein beta-8 (HSPB8/Hsp22) & 0.15 & n.d. & n.a. & 0.0053 \\
\hline Epoxide hydrolase 1 & 0.15 & n.d. & n.a. & 0.0461 \\
\hline Y-box-binding protein 3 (YBX3) & 0.12 & n.d. & n.a. & 0.0141 \\
\hline 605 ribosomal protein L22 & 0.12 & n.d. & n.a. & 0.0490 \\
\hline 605 ribosomal protein L7 & 0.10 & n.d. & n.a. & 0.0330 \\
\hline Collagen alpha-3(IV) chain & 0.09 & n.d. & n.a. & 0.0337 \\
\hline CD59 glycoprotein & 0.09 & n.d. & n.a. & 0.0333 \\
\hline SET-binding protein & 0.09 & n.d. & n.a. & 0.0333 \\
\hline 78 kDa glucose-regulated protein (GRP78/BiP) & 0.29 & 0.05 & 5.7 & $0.0526^{*}$ \\
\hline Cysteine and glycine-rich protein 3 (CSRP3) & 0.21 & 0.08 & 2.8 & $0.0504^{*}$ \\
\hline Delta-sarcoglycan & 0.07 & n.d. & n.a. & $0.0781^{*}$ \\
\hline Thrombospondin-4 & 0.07 & n.d. & n.a. & $0.0727^{*}$ \\
\hline
\end{tabular}

n.d. not detected, n.a. not applicable. Protein names marked in bold letters: proteins included in immunolocalization studies $p$ value between 0.05 and 0.1 but validated by immunofluorescence studies

a per mill of total spectral counts

Subsequently, a tryptic in solution-digestion was performed as described [18].

\section{Mass spectrometry and relative protein quantification}

The samples were analyzed by nanoHPLC-ESI-MS/MSanalysis. Nano-HPLC was performed on an UltiMate 3000 RSLC nano LC system (Thermo Fisher Scientific, Dreieich, Germany). Samples were loaded on a trap column (Acclaim ${ }^{\oplus}$ PepMap 100, $100 \mu \mathrm{m} \times 2 \mathrm{~cm}, \mathrm{C} 18$, particle size $5 \mu \mathrm{m}$, pore size $100 \AA$ ) with $0.1 \%$ TFA (flow rate $10 \mu \mathrm{l} / \mathrm{min})$. After sample concentration and a washing step the trap column was serially connected with an analytical column (Acclaim ${ }^{\circ}$ PepMap RSLC, $75 \mu \mathrm{m}$ x $50 \mathrm{~cm}$, C18, particle size $2 \mu \mathrm{m}$, pore size $100 \AA$ ), and peptides were separated with a flow rate of $400 \mathrm{nl} / \mathrm{min}$ by using a solvent gradient from $4 \%$ A to $40 \%$ B (A: $0.1 \%$ FA, B: $84 \%$ acetonitrile, $0.1 \%$ FA) for $95 \mathrm{~min}$. The HPLC system was directly coupled to a nanoelectrospray ionization source of a LTQ Orbitrap Elite mass spectrometer (Thermo Fisher Scientific, Dreieich, Germany). Ionization was performed using a nanoelectrospray source with a spray voltage of $1500 \mathrm{~V}$ and capillary temperature of $275{ }^{\circ} \mathrm{C}$. The 


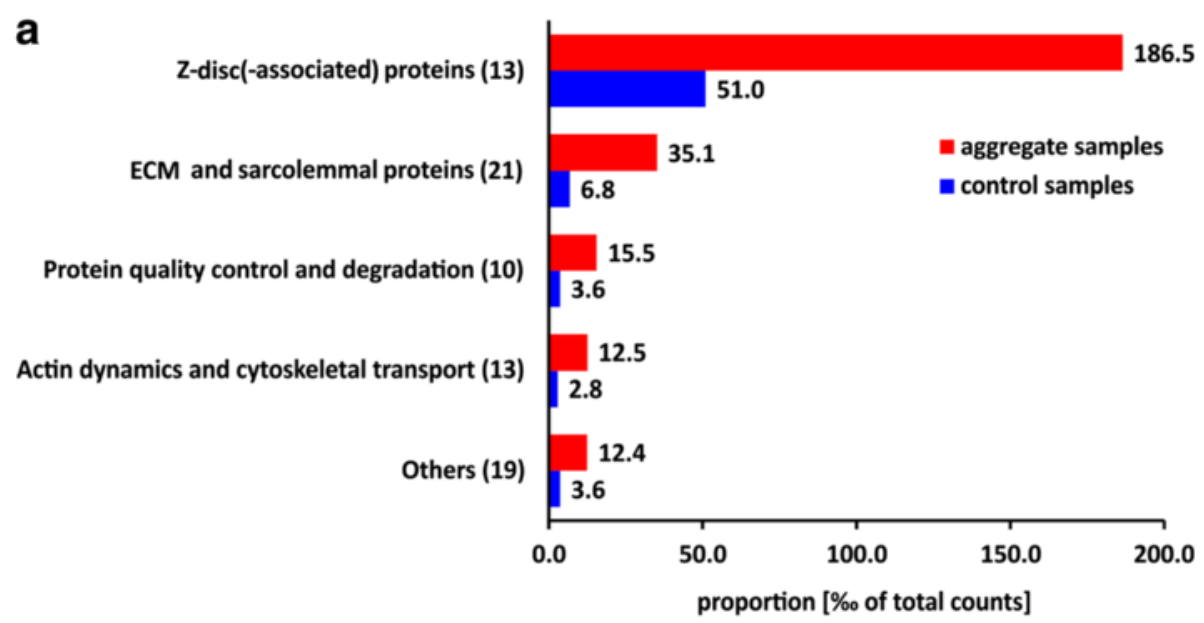

b

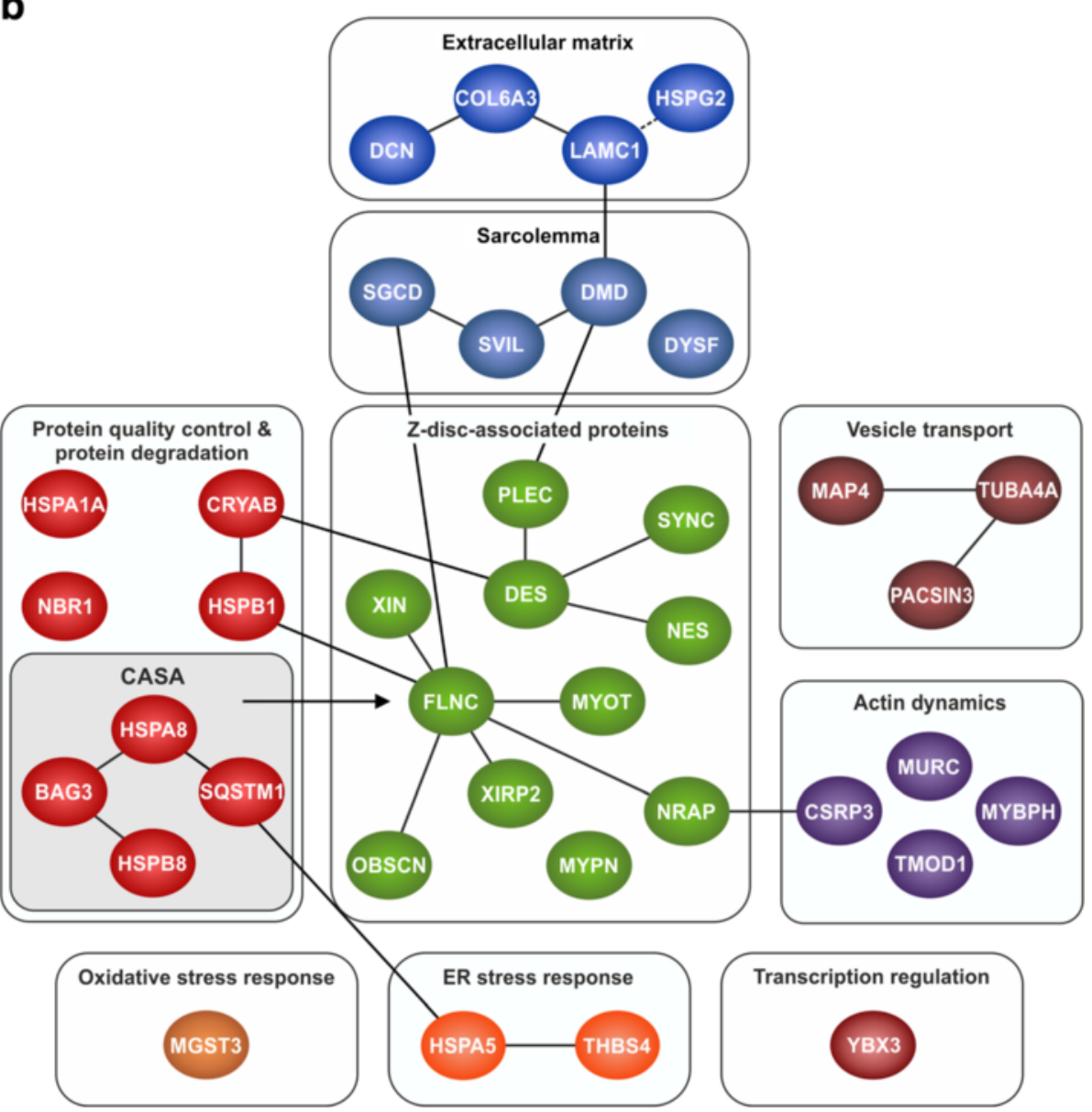

Fig. 2 Functional classification and interactions of proteins identified as over-represented in myotilinopathy aggregates samples. a Results of proteomic analysis in myotilinopathy. Proteins identified as over-represented in aggregate samples by mass spectrometric analysis are grouped with regard to their localization or main function. Shown are proportions in aggregate and control samples. Z-disc (-associated) proteins constituted the most abundant group of over-represented proteins, followed by proteins of the sarcolemma and extracellular matrix (ECM), proteins involved in protein quality control and degradation and proteins with a function in actin dynamics or cytoskeletal transport. b Schematic illustration of over-represented proteins which were verified by immunofluorescence studies and of protein-protein interactions. Each protein is termed by the name of its encoding gene (see Additional file 2: Table S2). Direct protein interactions, identified by review of the literature, are depicted by solid connecting lines. Indirect protein interactions are depicted by a dashed connecting line 


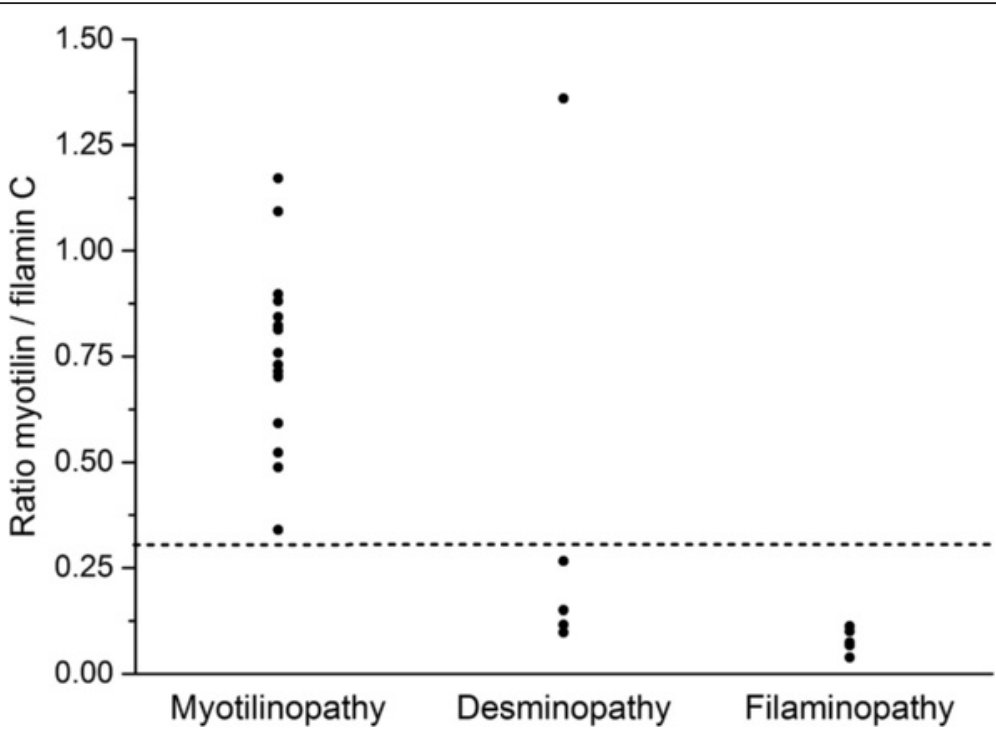

Fig. 3 Individual myotilin/filamin C ratios in aggregate samples from myotilinopathy, desminopathy and filaminopathy patients. Proportions of myotilin and filamin C in aggregate samples were determined by our proteomic approach. The myotilin/filamin C ratio was always above 0.3 in samples from 15 myotilinopathy patients and below 0.3 in all filaminopathy cases $(n=6)$ and in 4 out of 5 desminopathy patients

mass spectrometer was operated in a data dependent acquisition. Full MS spectra were scanned between 300 and $2000 \mathrm{~m} / \mathrm{z}$ (resolution 60,000, AGC $1 \times 10^{6}$ ) to detect precursor ions. Lock mass polydimethylcyclosiloxane $(\mathrm{m} / \mathrm{z} 445.120)$ was used for internal calibration.
The $\mathrm{m} / \mathrm{z}$ values initiating MS/MS were set on a dynamic exclusion list for $35 \mathrm{~s}$ and the 20 most intensive ions (charge >1) were selected for MS/MS-fragmentation. Fragments were generated by low-energy collisioninduced dissociation with normalized collision energy of

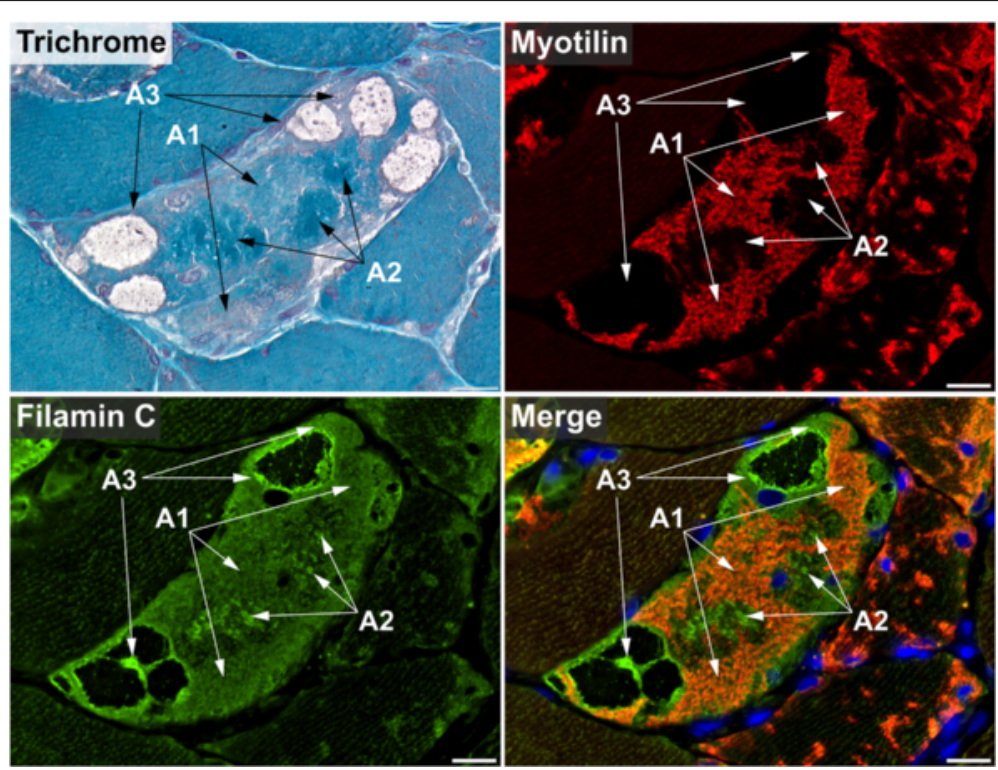

Fig. 4 Abnormal areas in skeletal muscle fibers with protein aggregates in myotilinopathy. Serial skeletal muscle cryosections from a myotilinopathy patient (ID1 in Table 1) were stained with modified Gomori trichrome and double-immunostained with primary antibodies directed against myotilin and filamin C. DAPI was used to visualize nuclei. Three different areas of protein accumulation were detected in abnormal fibers: Abnormal areas A1 appear hyaline on trichrome stain and are characterized by aggregation of myotilin and several other proteins (see Table 3) including filamin C. Abnormal areas A2 are located in the sarcoplasm of abnormal fibers, appear dark blue in trichrome stain and are characterized by a decreased immunoreactivity for myotilin and a strong accumulation of filamin C (among other proteins, see Table 3). Abnormal areas 3 are located around subsarcolemmal vacuoles in abnormal fibers, appear hyaline-purple in trichrome stain and show a decreased immunoreactivity for myotilin and an increased immunoreactivity for filamin $\mathrm{C}$ (and other proteins, see Table 3). Scale bar $=20 \mu \mathrm{m}$ 

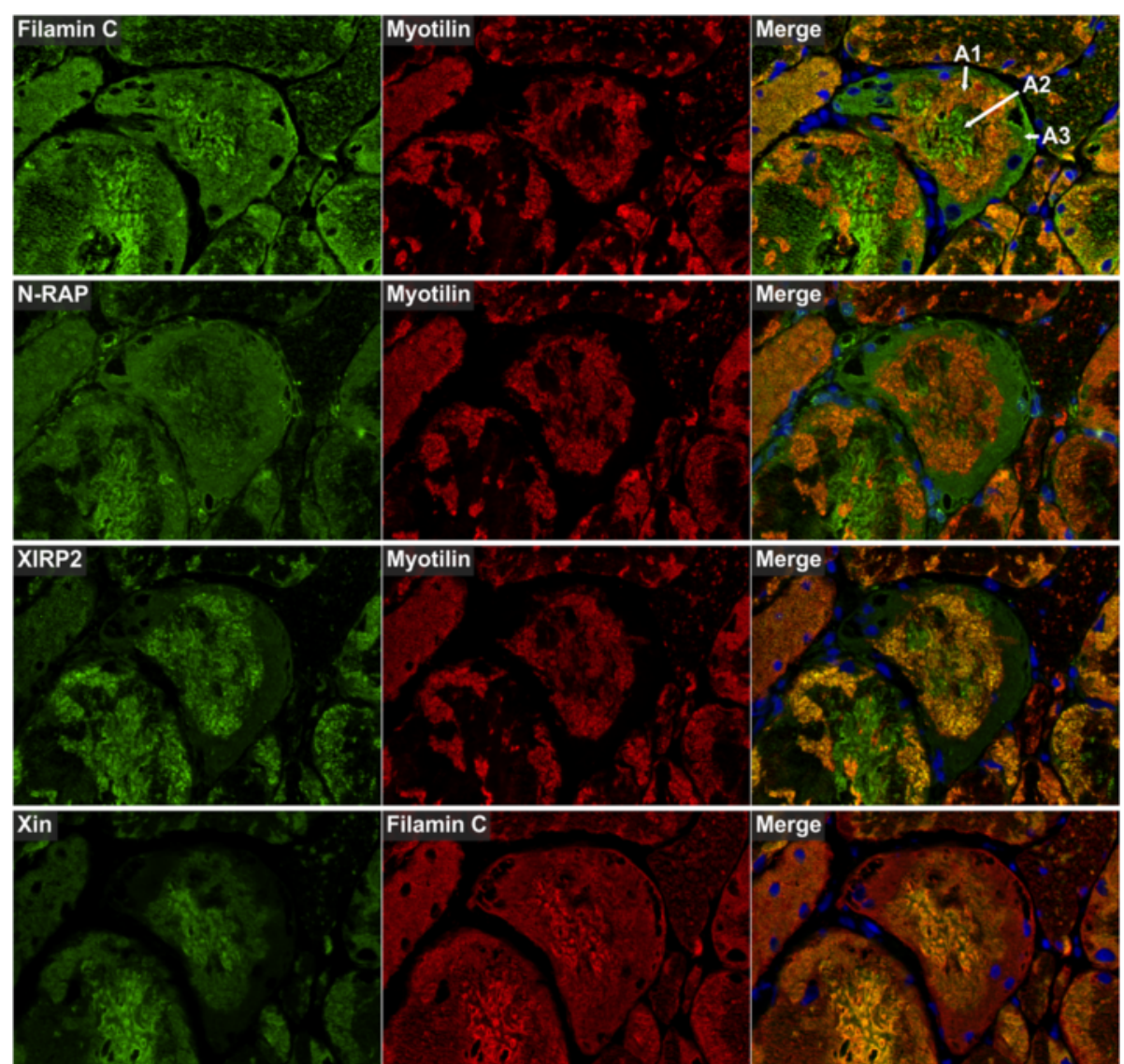

Filamin C

Merge
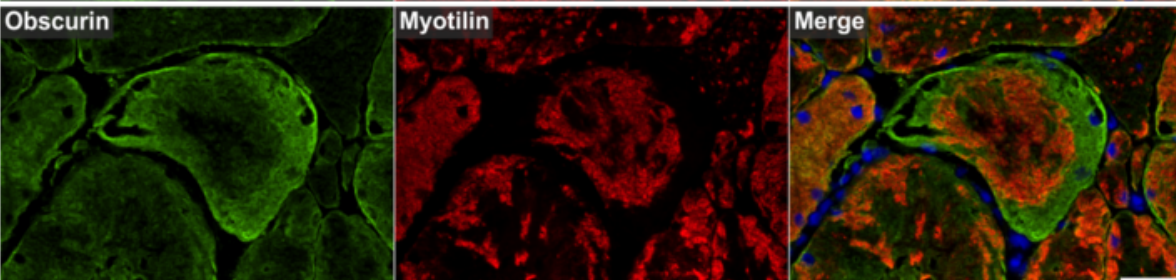

Fig. 5 Immunolocalization of Z-disc (-associated) proteins I. Serial skeletal muscle cryosections from a myotilinopathy patient (ID1 in Table 1) were double-stained with antibodies recognizing the indicated Z-disc (-associated) proteins and either filamin C or myotilin as a positive control to localize abnormal fibers. Nuclei were visualized by DAPI staining. Results of semiquantitative evaluation of signal intensities in the different abnormal areas A1-A3 are specified in Table 3. A1: abnormal area 1; A2: abnormal area 2; A3: abnormal area 3. Scale bar $=50 \mu m$

$35 \%$ (isolation width 2, activation time $10 \mathrm{~ms}$ ). After ESIMS/MS analysis mass spectrometric data were searched against a human protein database containing the entire Uniprot/Swissprot (release 2014/10, 546,790 entries) using Mascot search engine (Matrixscience, London, UK) with the following search parameters: peptide mass tolerance $10 \mathrm{ppm}$, fragment mass tolerance $0.5 \mathrm{Da}$, one missed cleavage and carbamidomethylation $(\mathrm{C})$, oxidation $(\mathrm{M})$, phosphorylation $(\mathrm{S}, \mathrm{T}, \mathrm{Y})$ as variable modifications. The quality of identified peptide spectrum matches was evaluated by calculating a FDR threshold of $1 \%$ using the in-house developed software "PIA-Protein Inference Algorithm" [19] (http://mpc-bioinformatics.github.io/pia/).
Only peptides that were unique within the complete data set were considered for final analysis to prevent an assignment to different proteins due to sequence homologies. Protein quantification was performed by summing up all peptide spectrum matches (hereinafter referred as "spectral counts") belonging to the respective protein followed by a normalization step. For normalization the proportion (in \%) of spectral counts for each protein based on total sum of spectral counts in the individual samples was calculated. To identify proteins that were over-represented in aggregate samples, the ratios between the averaged proportions in aggregate and control samples were calculated and a two-tailed unpaired 

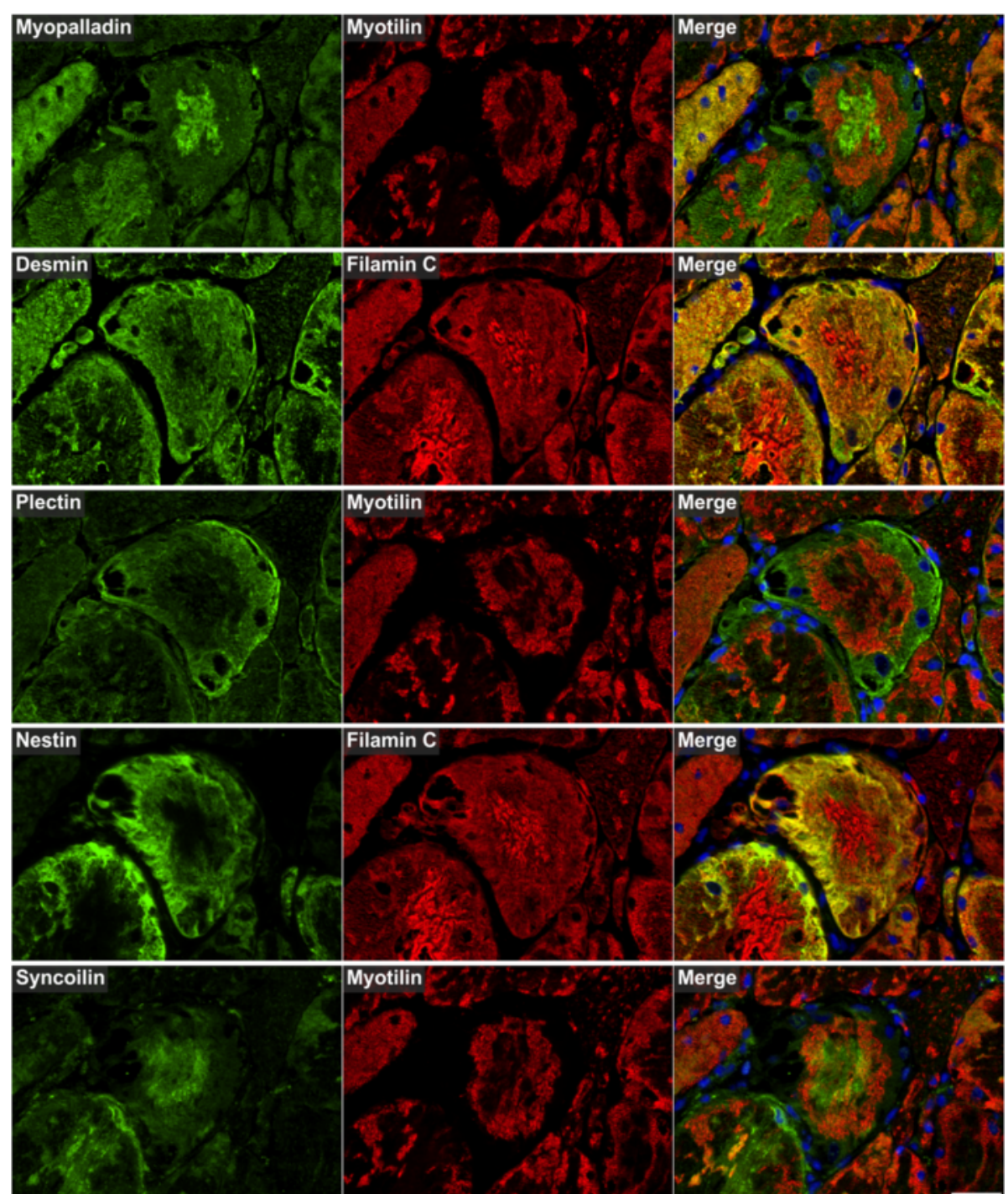

Fig. 6 Immunolocalization of Z-disc (-associated) proteins II. Double immunofluorescence staining was performed on serial skeletal muscle cryosections from a myotilinopathy patient (ID1 in Table 1) using antibodies directed against myopalladin, desmin, plectin, nestin, and syncoilin and either filamin C or myotilin. Nuclei were visualized by the blue-fluorescent DAPI nucleic acid stain. Data of semiquantitative assessment of immunofluorescence intensities in abnormal areas A1-A3 are listed in Table 3. Scale bar $=50 \mu \mathrm{m}$

t-test (equal variances assumed) was conducted for each protein. A protein was considered as significantly overrepresented when the aggregate to control ratio was $>1.5$ and the $p$-value $<0.05$. In addition, we compared the results of proteomic analysis in myotilinopathy patients with data from our previous studies in filaminopathy and desminopathy [17, 18] using the same modified parameters described above. For identification of diagnostic markers for myotilinopathy, proteomic data from 10 myotilinopathy patients (ID 1-10) were evaluated for differences in ratios and proportions of proteins compared to findings in filaminopathy and desminopathy. Potential markers were subsequently checked in the remaining 5 myotilinopathy patients (ID
$11-15)$ in a prospective manner. Specificity and sensitivity were calculated using $2 \times 2$ contingency tables.

\section{Validation of proteomic data by immunolocalization studies}

We used double immunofluorescence staining to assess the localization of selected proteins that were identified as over-represented in aggregate samples by our proteomic analysis. 5- $\mu \mathrm{m}$-thick serial frozen skeletal muscle sections from three myotilinopathy patients (IDs 1,10 and 11) were incubated overnight at $4{ }^{\circ} \mathrm{C}$ with primary antibodies directed against 40 different proteins (Additional file 1: Table S1). Myotilin or filamin C immunostaining was used to identify abnormal fibers with protein deposits. After 

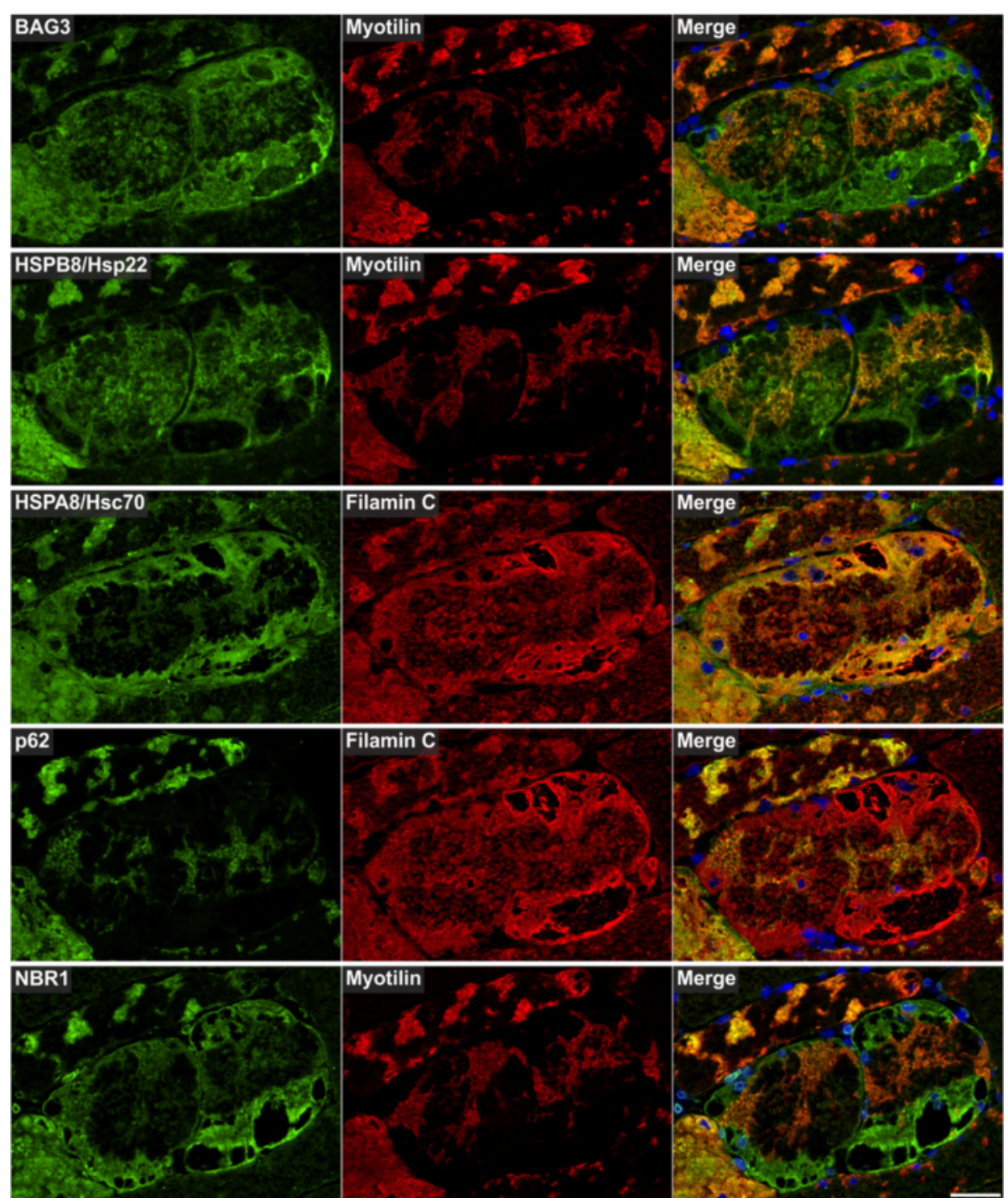

Fig. 7 Immunolocalization of proteins involved in chaperone-assisted selective autophagy (CASA) and NBR1-mediated selective autophagy. Serial skeletal muscle cryosections from a myotilinopathy patient (ID1 in Table 1) were double-stained with antibodies recognizing the indicated CASA components (BAG3, HSPB8/Hsp22, HSPA8/Hsc70, p62) and NBR1 and either filamin C or myotilin. Nuclei were visualized by DAPI staining. Results of semiquantitative evaluation of signal intensities in the different abnormal areas A1-A3 are specified in Table 3. Scale bar $=50 \mu \mathrm{m}$

three washing steps with PBS for 5 min the sections were incubated with isotype specific secondary antibodies conjugated with DyLight 488 (Dianova, Hamburg, Germany; dilution 1:1000) or Texas Red (Jackson Immuno Research, West Grove, Pennsylvania, USA; dilution 1:500) for $45 \mathrm{~min}$ at RT, followed by three washing steps with PBS for $5 \mathrm{~min}$. Nuclei were displayed by incubation with 4, 6-diamidino-2phenylindole (DAPI) (Roche Diagnostics, Indianapolis, IN, USA; dilution $1: 10,000$ ) for $1 \mathrm{~min}$ at $37{ }^{\circ} \mathrm{C}$. The staining procedure was finished by two washing steps with PBS for 5 min. Stained sections were mounted in Roti ${ }^{\ominus}$-Mount FluorCare (Carl Roth, Karlsruhe, Germany) and analyzed using an IX83 inverted microscope system (Olympus, Hamburg, Germany).

\section{Results}

\section{Proteomic analysis in myotilinopathy}

Mass spectrometric analysis of aggregate and control samples identified 1002 different proteins. 72 of these proteins showed a statistically significant over-representation in aggregate samples with a ratio $>1.5$ compared to control samples (Table 2, for UniProtKB/Swiss-Prot accession numbers and gene names see Additional file 2: Table S2). Although the last four proteins in Table 2 were detected as over-represented in aggregate areas with their individual $\mathrm{p}$ values (between 0.05 and 0.08 ) slightly below the level of statistical significance, these proteins were also evaluated by immunofluorescence studies. The results confirmed an accumulation in abnormal muscle fibers (see below). 

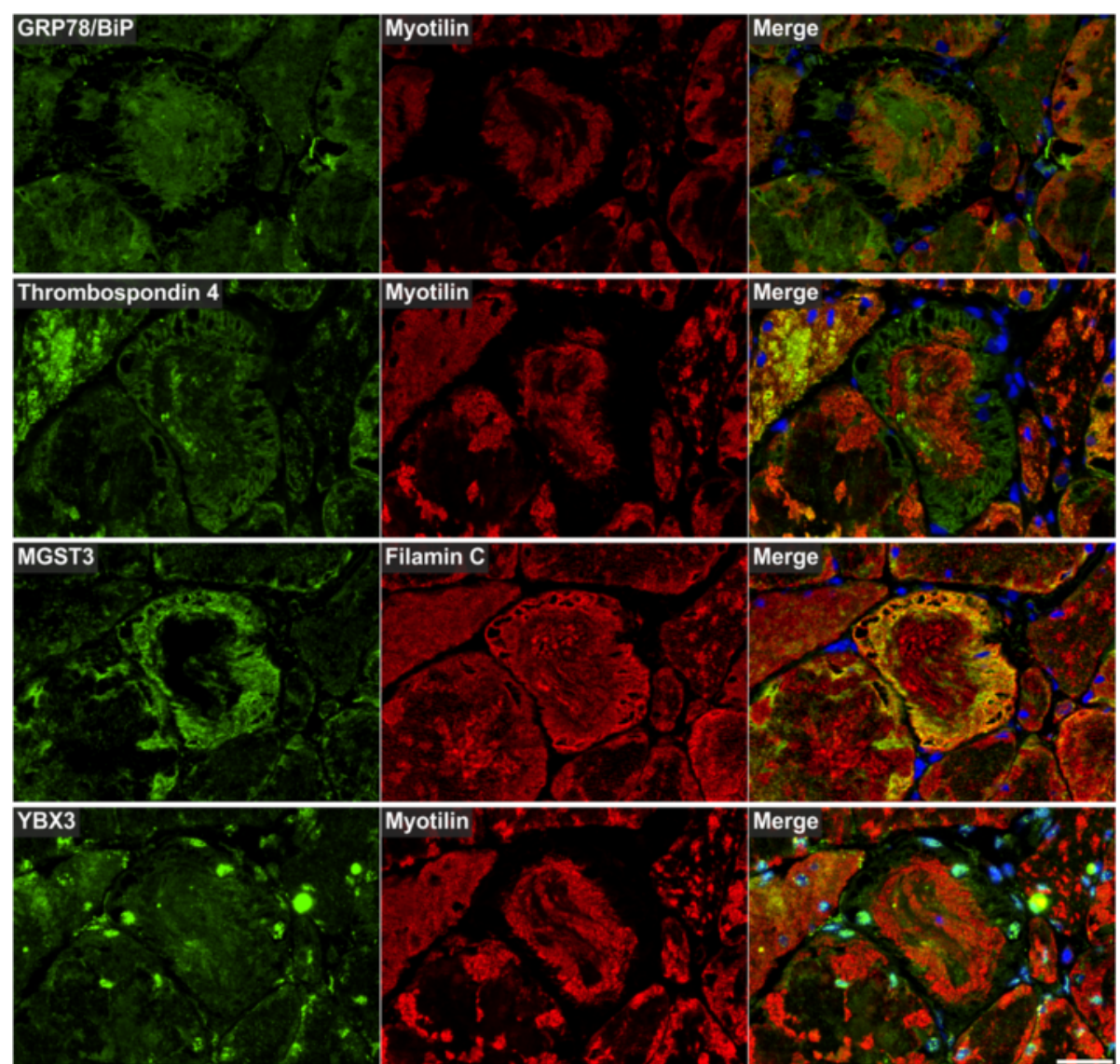

Fig. 8 Immunolocalization of proteins involved in unfolded protein response (UPR), oxidative stress response and transcription regulation. Serial skeletal muscle cryosections from a myotilinopathy patient (ID1 in Table 1) were double-stained with antibodies recognizing GRP78/BiP, thrombospondin 4 (both involved in UPR), MGST3 (related to oxidative stress response), and YBX3 (transcription regulation) and either filamin C or myotilin. Nuclei were visualized by DAPI staining. Results of semiquantitative evaluation of signal intensities in the different abnormal areas A1-A3 are specified in Table 3. Scale bar $=50 \mu \mathrm{m}$

A functional classification of proteins by review of the literature revealed that Z-disc and Z-disc-associated proteins, including the disease causing protein myotilin, were most abundantly over-represented in aggregate samples, followed by sarcolemmal and extracellular matrix proteins, proteins involved in protein quality control and degradation, and proteins with a function in actin dynamics or cytoskeletal transport (Fig. 2). Proteomic profiles of aggregates collected from different muscles were largely homogeneous and independent of the specific MYOT mutation (Additional file 3: Figure S1).

\section{Comparison of mass spectrometric analysis in different MFM subtypes}

The comparison of data from proteomic analysis in myotilinopathy, filaminopathy and desminopathy revealed that desmin, filamin $\mathrm{C}$, myotilin, N-RAP, Xin, Xirp2, $\alpha \mathrm{B}-$ crystallin, and nestin were always over-represented in aggregate samples irrespective of the MFM subtype, although differences in ratios and proportions were detected. The ratio of the myotilin and filamin $\mathrm{C}$ proportions in aggregate samples was identified as a new diagnostic marker for myotilinopathy with a high sensitivity $(100 \%)$ and specificity (91 \%) in our MFM cohort (Fig. 3). This ratio was always above 0.3 in samples from myotilinopathy patients (range 0.34-1.17) and below 0.3 in all filaminopathy (range $0.07-0.1$ ) and in 4 out of 5 desminopathy patients (range 0.11-0.26).

Our previous proteomic studies [18] identified the filamin $\mathrm{C}$ ratio (proportion in aggregate samples divided by proportion in control samples) as a diagnostic marker to differentiate filaminopathy from desminopathy. This ratio was always above 6 in filaminopathy samples (range 6.6-8.6) and below 5 in desminopathy samples (range 1.9-4.5). Our data presented here revealed an intraindividual filamin $\mathrm{C}$ ratio below 4 (range 1.1-3.9) in all 15 myotilinopathy patients indicating that the filamin $\mathrm{C}$ ratio is also suited for differentiation of filaminopathy from myotilinopathy (sensitivity of this diagnostic marker to detect filaminopathy in our MFM cohort $100 \%$, specificity $100 \%)$. 

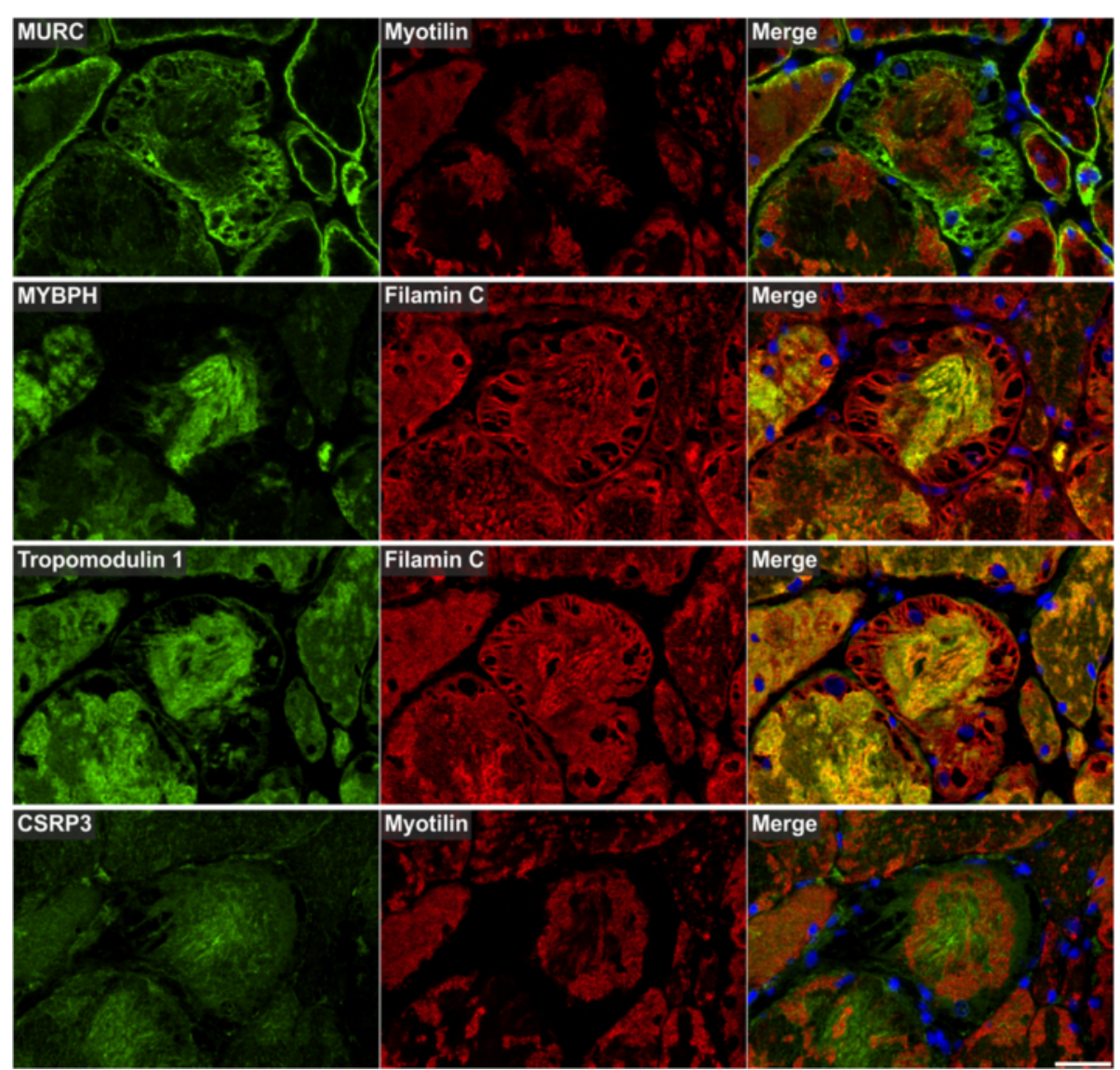

Fig. 9 Immunolocalization of proteins involved in actin dynamics. Double immunofluorescence staining was performed on serial skeletal muscle cryosections from a myotilinopathy patient (ID1 in Table 1) by using antibodies directed against MURC, MYBPH, tropomodulin 1, and CSRP3 (a Z-disC protein that is also involved in actin dynamics) and either filamin C or myotilin. Nuclei were visualized by the blue-fluorescent DAPI nucleic acid stain. Data of semiquantitative assessment of immunofluorescence intensities in abnormal areas A1-A3 are listed in Table 3. Scale bar $=50 \mu m$

\section{Validation of proteomic data by immunofluorescence studies}

Our extensive immunolocalization studies confirmed the results of proteomic analysis. Forty proteins detected as over-represented in aggregate samples also showed increased immunoreactivities in fibers harboring protein aggregates. However, the distribution pattern of protein accumulation varied considerably between individual proteins.

Myotilin localized in sarcoplasmic aggregates of variable size and shape (Figs. 4, 5, 6, 7, 8, 9, 10,11 and 12). The proportion of abnormal fibers with myotilin-positive aggregates varied between $<10 \%$ and $>50 \%$ in sections of muscle samples from different patients (Additional file 4: Figure S2). Consistent with proteomic analysis, other proteins assessed by immunofluorescence studies also showed an accumulation in at least a part of the myotilin-positive protein deposits (Figs.. 4, 5, 6, 7, 8, 9, 10, 11 and 12). Outside these areas, immunoreactivity for myotilin was usually decreased (Additional file 5: Figure S3) in abnormal fibers, whereas the signal intensities of other evaluated proteins were partly (locally) increased (Figs. 4, 5, 6, 7, 8, 9, 10, 11 and 12). Based on our immunofluorescence findings, we defined three different areas in abnormal fibers (Fig. 4):

Abnormal areas A1: areas with myotilin aggregation (Fig. 4).

Abnormal areas A2: sarcoplasmic areas showing a decreased immunoreactivity for myotilin but a strong accumulation of a subset of Z-disc proteins, chaperones and proteins involved in sarcoplasmic reticulum stress and actin dynamics (Figs. 4, 5, 6, 7, 8, 9, 10 and 11, Table 3).

Abnormal areas A3: areas surrounding subsarcolemmal vacuoles (Fig. 4) with decreased or absent myotilin immunoreactivity, but strong accumulation of most of the other evaluated proteins (Figs. 4, 5, 6, 7, 8, 9, 10, 11 and 12, Table 3). Intact myofibrils were not observed in A3 areas (Additional file 6: Figure S4)

The results of our extensive comparative immunolocalization studies of i) Z-disc proteins (Figs. 5 and 6), ii) proteins involved in chaperone-assisted selective autophagy (CASA) and NBR1-mediated selective autophagy (Fig. 7), 

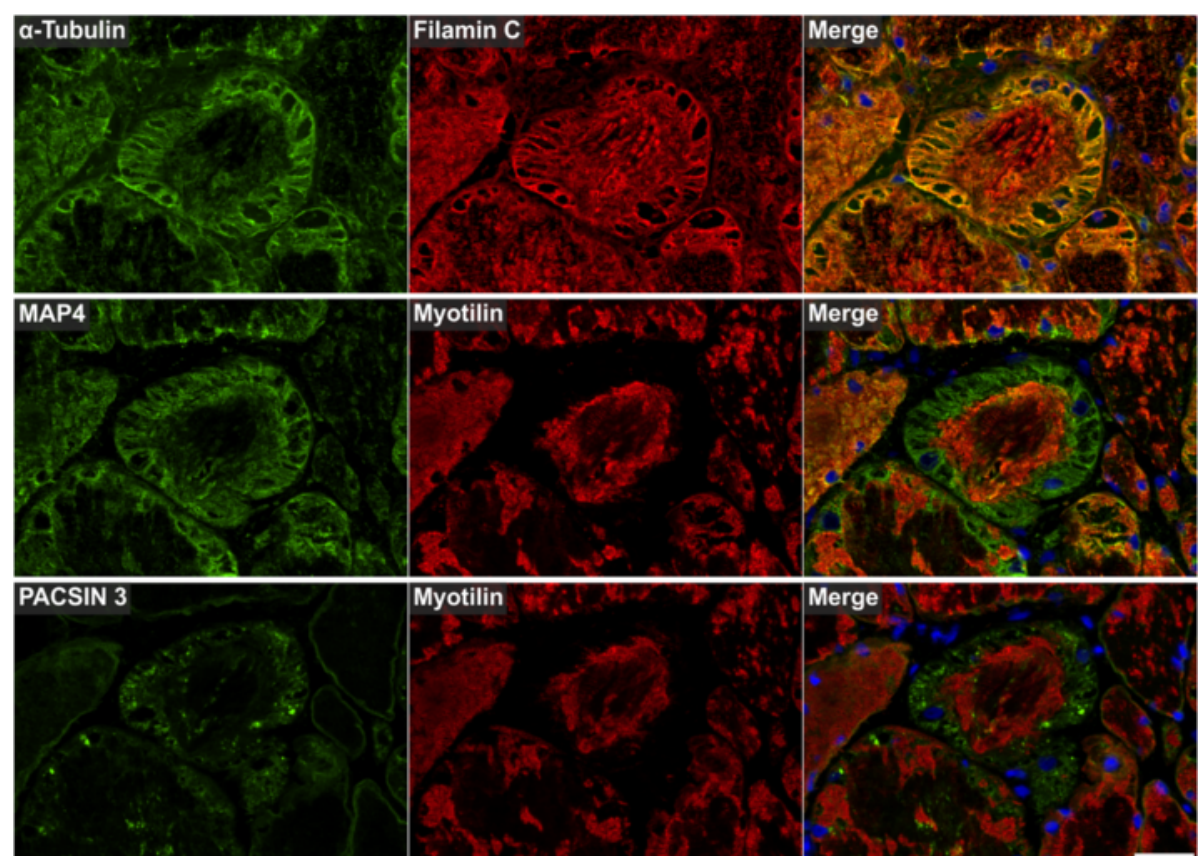

Fig. $10 \mathrm{Immunolocalization} \mathrm{of} \mathrm{proteins} \mathrm{involved} \mathrm{in} \mathrm{microtubule} \mathrm{organization} \mathrm{and} \mathrm{vesicle} \mathrm{transport.} \mathrm{Serial} \mathrm{skeletal} \mathrm{muscle} \mathrm{cryosections} \mathrm{from} \mathrm{a}$ myotilinopathy patient (ID1 in Table 1) were double-stained with antibodies recognizing a-Tubulin, MAP4, and PACSIN3 and either filamin C or myotilin. Nuclei were visualized by DAPI staining. Results of semiquantitative evaluation of signal intensities in the different abnormal areas A1-A3 are specified in Table 3. Scale bar $=50 \mu \mathrm{m}$

iii) other chaperones and proteins that play a role in unfolded protein response, oxidative stress and transcription regulation (Fig. 8 and Additional file 7: Figure S5), iv) proteins involved in actin dynamics (Fig. 9) and microtubule organization and vesicle transport (Fig. 10), and v) sarcolemmal proteins (Fig. 11) are depicted in the respective figures. Immunofluorescence stainings of control muscle fibers are displayed in Additional file 8: Figure S6. H\&E and modified Gomori trichrome stains of muscle fibers presented in Figs. 5, 6, 7, 8, 9, 10 and 11 are shown in Additional file 4: Figure S2. Results of semiquantitative assessment of immunofluorescence signal intensities in areas A1-A3 (compared to normally looking intraindividual control fibers) are listed in Table 3.

Extracellular matrix (ECM) proteins showed an ectopic cytoplasmic expression only in some abnormal fibers (Fig. 12). Collagen VI and laminin displayed a diffuse staining pattern in areas of filamin $\mathrm{C}$ aggregation. Collagen VI also strongly accumulated in some areas lacking immunoreactivity for filamin C (Fig. 12). Perlecan and decorin immunoreactivity was especially increased in areas between and around myotilin-positive aggregates (Fig. 12). 14-3-3 $\gamma$ protein showed an increased immunofluorescence signal predominantly in angulated fibers with filamin $\mathrm{C}$ aggregates (Additional file 9: Figure S7). Lamin A/C was located at the nuclear lamina and its over-representation in aggregate samples is obviously caused by centrally located nuclei in aggregate areas (Additional file 7: Figure S5).

\section{Discussion}

Protein aggregation in muscle fibers is the most impressive histological feature of myofibrillar myopathies and seems to play a key role in their pathogenesis. We provide here proteomic data of laser-microdissected sarcoplasmic aggregates from 15 myotilinopathy patients, the largest MFM subtype cohort that has been studied by mass spectrometric analysis so far. The comparison with intraindividual control samples enabled us the identification of proteins which are over-represented in aggregates and therefore appear to be relevant for aggregate formation or modulation. Our innovative approach revealed essential new information about aggregate composition in myotilinopathy that pave the way for future functional studies to investigate disease mechanisms. Furthermore, we identified a novel diagnostic biomarker that can be helpful in differential diagnosis of protein aggregate myopathies.

More than 1000 different proteins were detected by our proteomic analysis of muscle samples from myotilinopathy patients and 72 of them showed a statistically significant over-representation in aggregate samples. Thirty-six of these 72 proteins were further evaluated by immunofluorescence studies on muscle sections from patients. These analyses confirmed and thus validated our mass spectrometric results. In addition, we studied the subcellular distribution of four additional, functionally interesting proteins (GRP78/BiP, CSRP3, 

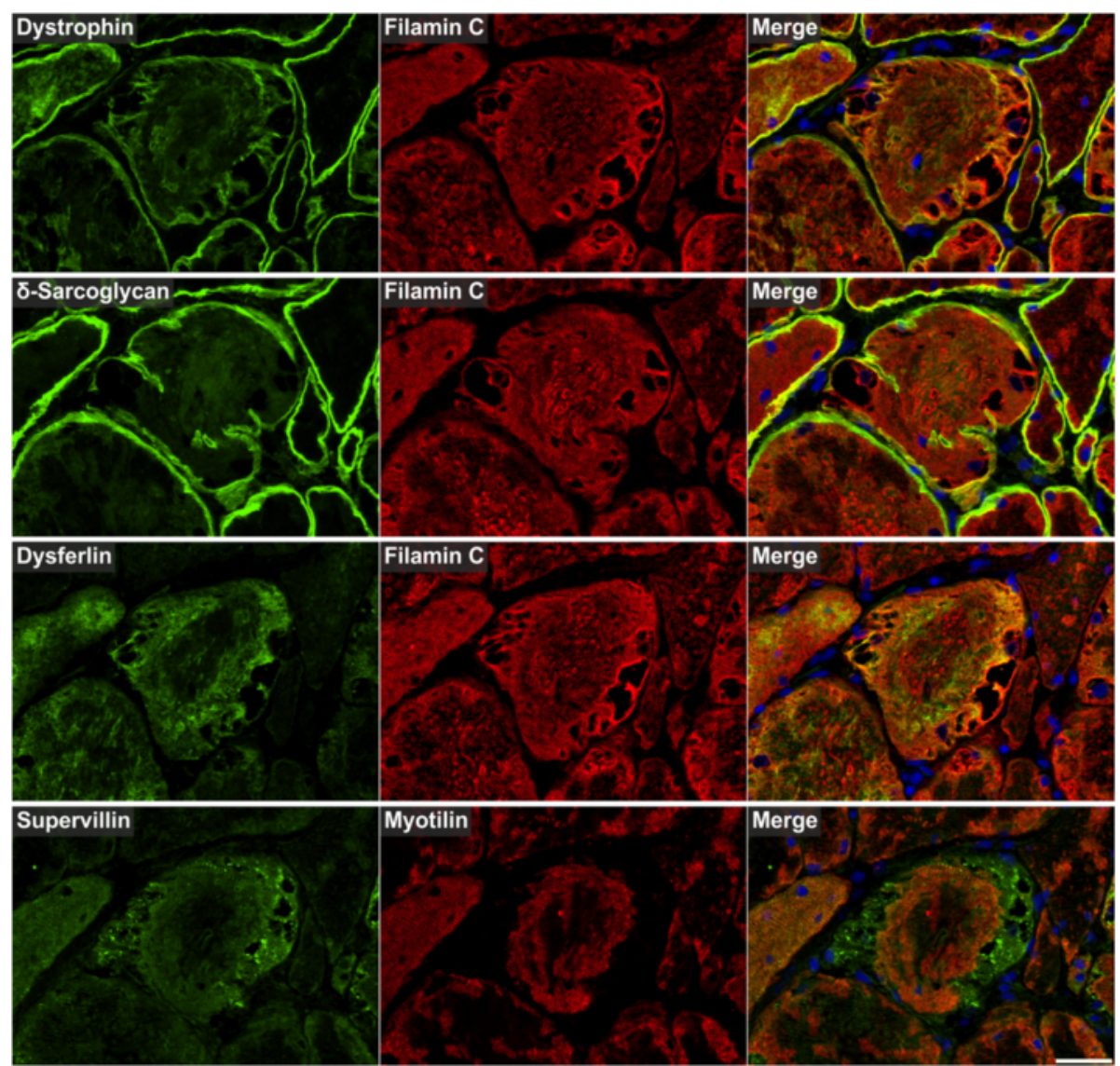

Fig. 11 Immunolocalization of sarcolemmal proteins. Double immunofluorescence staining was performed on serial skeletal muscle cryosections from a myotilinopathy patient (ID1 in Table 1) by using antibodies directed against the sarcolemmal proteins dystrophin, dysferlin, supervillain, and $\delta$-sarcoglycan and either filamin C or myotilin. Nuclei were visualized by the blue-fluorescent DAPI nucleic acid stain. Data of semiquantitative assessment of immunofluorescence intensities in abnormal areas A1-A3 are listed in Table 3. Scale bar =50 $\mu \mathrm{m}$

$\delta$-sarcoglycan, thrombospondin 4), which were identified as over-represented in aggregate samples but slightly missed the level of statistical significance. We found that abnormal fibers also displayed an increased immunoreactivity for these proteins. Only ten of the in total 76 proteins that were enriched in aggregates were previously described components of deposits in myotilinopathy, namely myotilin $[4,11]$, desmin $[4,11]$, filamin $C[13,20]$, $\alpha B$-crystallin [4, 11], Xin [16], Xirp2 [16], plectin [11], dystrophin $[4,11]$, NBR1 [21] and p62 [15]. This implies that 66 aggregate proteins were newly identified. However, considering the large number of identified proteins, false positive results cannot be ruled out. We therefore focus our discussion on findings that we could verify by immunolocalization studies.

We categorized the detected proteins by their main function and found that Z-disc-associated proteins were the most abundant aggregate components. More than $70 \%$ of peptides from over-represented proteins were assigned to this group and the proportion of these Z-disc proteins related to the total number of identified peptides was 3.7 fold higher in aggregate samples compared to controls. Referred to the proportion of specific over-represented proteins in aggregate samples (see [17] for a discussion of limitations of our proteomic approach), myotilin was one of the top proteins. Only desmin and filamin $\mathrm{C}$ showed a higher proportion than myotilin. Most of the other Z-disc proteins identified as accumulated in aggregate samples are interaction partners of desmin or filamin C: plectin, syncoilin, and nestin bind to desmin [22-24] and Xin, Xirp2, obscurin, and N-RAP interact with filamin C $[17,25]$. Desmin and filamin $C$ are indirectly connected via sarcolemmal proteins $[9,24,26,27]$ and chaperones $[17,28-30]$ that also showed an over-representation in aggregate samples (see Fig. 2). Our results therefore indicate that protein components of aggregates in myotilinopathy largely belong to a network of interacting proteins. This is in accordance with our findings in filaminopathy [17] and desminopathy [18] and suggests that MFM aggregates are rather structured formations than simple random depositions of aggregateprone proteins. The finding that Z-disc proteins are the most abundant over-represented proteins in aggregates also 

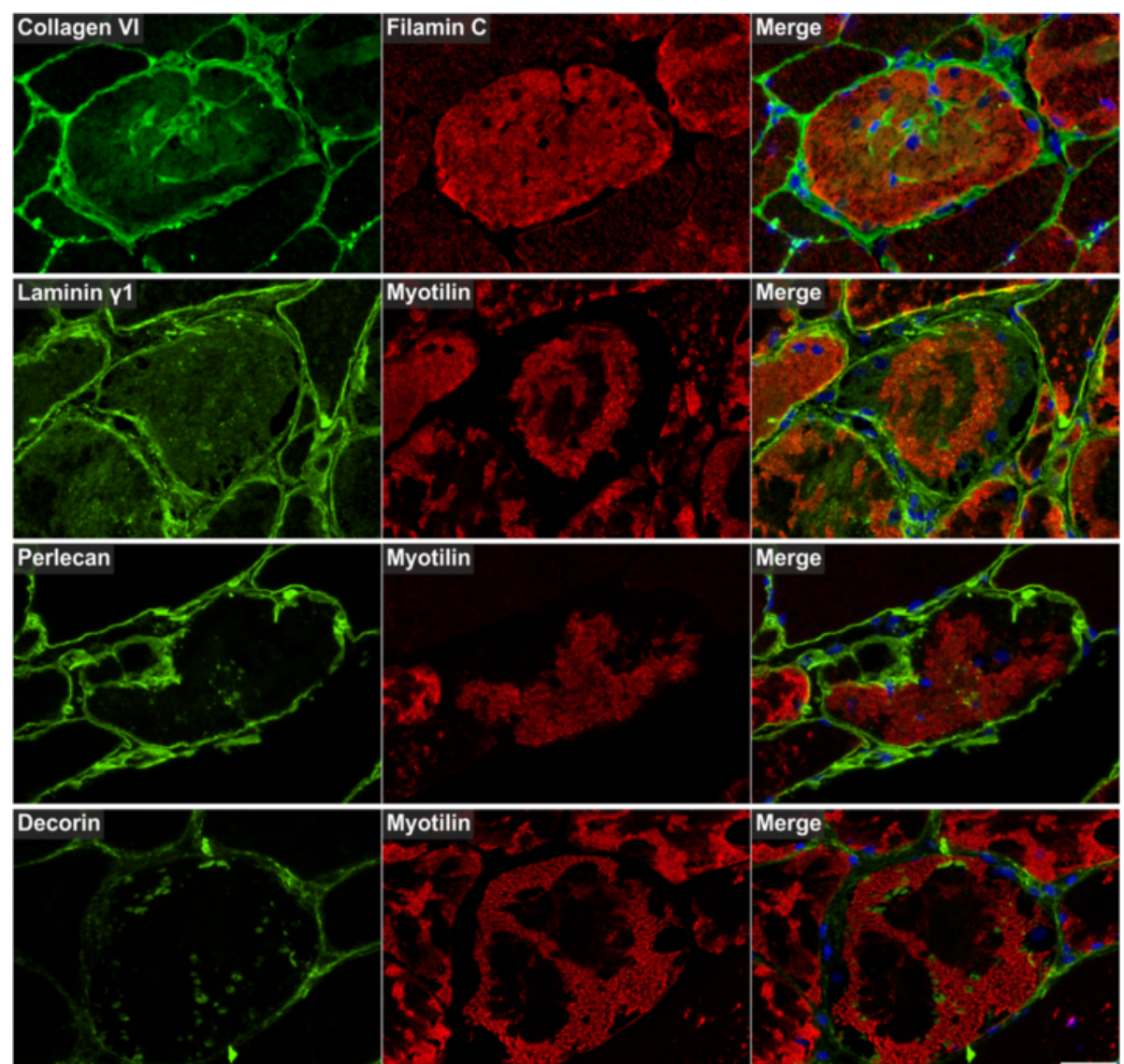

Fig. 12 Immunolocalization of extracellular matrix proteins. Serial skeletal muscle cryosections from a myotilinopathy patient (ID1 in Table 1) were double-stained with antibodies recognizing collagen VI, laminin $\gamma 1$, perlecan, and decorin and either filamin C or myotilin. Nuclei were visualized by DAPI staining. Some abnormal fibers showed an increased immunoreactivity for collagen $\mathrm{VI}$ and laminin $\gamma 1$ in areas of filamin $\mathrm{C}$ aggregation and collagen $\mathrm{VI}$ also a strong accumulation in some areas with lacking immunoreactivity for filamin C. Immunoreactivities for perlecan and decorin were predominantly increased in areas between and around myotilin-positive aggregates. Scale bar $=50 \mu \mathrm{m}$

corresponds to results of ultrastructural studies indicating that protein aggregation in MFM primarily emanates from Z-discs $[4,5]$.

The second group of aggregate components consists of sarcolemmal and extracellular matrix proteins. An accumulation of sarcolemmal proteins in aggregate areas has already been described in myotilinopathy and other MFM subtypes including filaminopathy and desminopathy $[4,11,16,31,32]$. This may be attributable to protein-protein interactions, e.g. of dystrophin with plectin [33] or between $\delta$-sarcoglycan and filamin $C$ [27]. However, the mechanisms by which extracellular matrix proteins are translocated to sarcoplasmic aggregates remain unclear. Since some of the detected ECM proteins (i.e. collagen VI) are not even expressed in skeletal muscle cells [34], it is tempting to speculate that they are translocated to the sarcoplasm via increased endocytosis. Indeed, we detected an accumulation of proteins in abnormal fibers which are involved in vesicle transport and endocytosis, e.g. PACSIN 3, but the relevance of this finding has to be further investigated.

The third group comprises proteins involved in protein quality control and degradation. A dysfunction of protein degradation mediated by the ubiquitin-proteasome system (UPS) and autophagic pathways seems to play a pivotal role in MFM [13, 15, 35, 36]. In this context, it is an interesting feature of all validated ECM proteins of group 2 that they modulate autophagic signaling pathways via interactions with specific receptors. Decorin, collagen VI and perlecan are activators of autophagy whereas laminin acts as inhibitor (see [37] for review). This demonstrates that several aggregate proteins have various functions and could be assigned to more than one group. The third group includes further proteins with an effect on autophagic protein degradation. The chaperone GRP78/BiP and thrombospondin 4 , both detected as over-represented in aggregate samples, are involved in endoplasmic reticulum stress and unfolded protein response. In addition, it has recently been shown that prolonged proteasomal 
Table 3 Semiquantitative evaluation of signal intensities in immunolocalization studies

\begin{tabular}{|c|c|c|c|}
\hline Protein & $\mathrm{A} 1$ & $\mathrm{~A} 2$ & $\mathrm{~A} 3$ \\
\hline \multicolumn{4}{|c|}{ Z-disc (-associated) proteins } \\
\hline Myotilin & $\uparrow \uparrow \uparrow$ & $\downarrow$ & $\downarrow /-$ \\
\hline Filamin C & $\uparrow \uparrow / \uparrow \uparrow \uparrow$ & $\uparrow \uparrow \uparrow$ & $\uparrow \uparrow / \uparrow \uparrow \uparrow$ \\
\hline N-RAP & $\uparrow \uparrow$ & $\uparrow \uparrow \uparrow$ & $\uparrow \uparrow$ \\
\hline XIRP2 & $\uparrow \uparrow / \uparrow \uparrow \uparrow$ & $\uparrow \uparrow \uparrow$ & $\uparrow$ \\
\hline Xin & $\uparrow \uparrow / \uparrow \uparrow \uparrow$ & $\uparrow \uparrow \uparrow$ & $(\uparrow)$ \\
\hline Obscurin & $\uparrow \uparrow$ & $\downarrow$ & $\uparrow \uparrow \uparrow$ \\
\hline Myopalladin & $\uparrow \uparrow / \uparrow \uparrow \uparrow$ & $\uparrow \uparrow \uparrow$ & $\uparrow / \uparrow \uparrow$ \\
\hline Desmin & $\uparrow \uparrow \uparrow$ & $(\uparrow)$ & $\uparrow \uparrow \uparrow$ \\
\hline Plectin & $\uparrow$ & $\downarrow$ & $\uparrow \uparrow \uparrow$ \\
\hline Nestin & $\uparrow / \uparrow \uparrow$ & - & $\uparrow \uparrow \uparrow$ \\
\hline Syncoilin & $\uparrow / \uparrow \uparrow$ & $\uparrow \uparrow \uparrow$ & $\uparrow / \uparrow \uparrow$ \\
\hline \multicolumn{4}{|c|}{$\begin{array}{l}\text { Chaperone-assisted selective autophagy (CASA)/NBR1-mediated } \\
\text { selective autophagy }\end{array}$} \\
\hline BAG3 & $\uparrow \uparrow / \uparrow \uparrow \uparrow$ & - & $\uparrow \uparrow \uparrow$ \\
\hline HSPB8/Hsp22 & $\uparrow \uparrow / \uparrow \uparrow \uparrow$ & $\uparrow \uparrow \uparrow$ & $\uparrow \uparrow \uparrow$ \\
\hline HSPA8/Hsc70 & $\uparrow \uparrow$ & $\uparrow$ & $\uparrow \uparrow \uparrow$ \\
\hline p62 & $\uparrow \uparrow \uparrow$ & $(\uparrow) / \uparrow \uparrow$ & $(\uparrow)$ \\
\hline NBR1 & $\uparrow \uparrow / \uparrow \uparrow \uparrow$ & $\uparrow$ & $\uparrow \uparrow / \uparrow \uparrow \uparrow$ \\
\hline \multicolumn{4}{|c|}{ Further chaperones } \\
\hline aB-crystallin & $\uparrow / \uparrow \uparrow$ & $\uparrow$ & $\uparrow \uparrow \uparrow$ \\
\hline HSPB1/Hsp27 & $\uparrow / \uparrow \uparrow$ & $\uparrow \uparrow \uparrow$ & $\uparrow \uparrow \uparrow$ \\
\hline Hsp70 & $\uparrow \uparrow$ & $\uparrow$ & $\uparrow \uparrow \uparrow$ \\
\hline
\end{tabular}

Unfolded protein response (UPR) / oxidative stress response/ transcription regulation

$\begin{array}{llll}\text { BiP } & \uparrow \uparrow & \uparrow \uparrow & (\uparrow) \\ \text { Thrombospondin 4 } & \uparrow \uparrow / \uparrow \uparrow \uparrow & \uparrow \uparrow \uparrow & \uparrow \uparrow \\ \text { MGST3 } & \uparrow \uparrow \uparrow & - & \uparrow \uparrow \uparrow \\ \text { YBX3 } & \uparrow / \uparrow \uparrow & \uparrow & \uparrow \\ \text { Actin dynamics } & & & \\ \text { MURC } & (\uparrow) / \uparrow \uparrow & (\uparrow) & \uparrow \uparrow \uparrow \\ \text { MYBPH } & (\uparrow) / \uparrow \uparrow \uparrow & \uparrow \uparrow \uparrow & (\uparrow) \\ \text { Tropomodulin 1 } & \uparrow \uparrow / \uparrow \uparrow \uparrow & \uparrow \uparrow \uparrow & (\uparrow) \\ \text { CSRP3 } & \uparrow & \uparrow \\ \text { Microtubule organization } / \text { vesicle transport } & & \\ \text { a-tubulin } & \uparrow \uparrow & \uparrow \uparrow & \\ \text { MAP4 } & \uparrow \uparrow / \uparrow \uparrow \uparrow & (\uparrow) & \uparrow \uparrow \uparrow \\ \text { PACSIN3 } & (\uparrow) / \uparrow \uparrow & - & \uparrow \uparrow \uparrow\end{array}$

Table 3 Semiquantitative evaluation of signal intensities in immunolocalization studies (Continued)

\begin{tabular}{llll}
\hline Sarcolemmal proteins & & & \\
Dystrophin & $\uparrow \uparrow$ & - & $\uparrow \uparrow / \uparrow \uparrow \uparrow$ \\
Dysferlin & $\uparrow \uparrow / \uparrow \uparrow \uparrow$ & $\uparrow$ & $\uparrow \uparrow / \uparrow \uparrow \uparrow$ \\
Supervillin & $\uparrow / \uparrow \uparrow$ & - & $\uparrow \uparrow \uparrow$ \\
S-Sarcoglycan & $(\uparrow)$ & $(\uparrow)$ & $(\uparrow)$ \\
\hline
\end{tabular}

A1: abnormal area 1, A2: abnormal area 2, A3: abnormal area 3; $(\uparrow) / \uparrow / \uparrow \uparrow / \uparrow \uparrow \uparrow:$ slightly/moderately/distinctly/strongly increased immunoreactivity compared to control fibers; $\downarrow$ : decreased immunoreactivity compared to control fibers; -: no visible immunoreactivity

inhibition and cytosolic misfolded proteins induce an $\mathrm{N}$-terminal arginylation of GRP78/BiP [38]. Arginylated GRP78/BiP (R-BiP) in turn associates with misfolded proteins and binds the autophagic adaptor p62. This finally induces a selective lysosomal codegradation of $\mathrm{R}-\mathrm{BiP}$ and $\mathrm{p} 62$ together with associated cargoes including misfolded proteins [38]. A strong immunoreactivity of myotilinopathy aggregates for p62 has already been reported [15]. Our proteomic analysis now revealed that the proportion of p62 in aggregate samples was 52-fold higher than in controls underlining the extreme extent of p62 enrichment in aggregate areas. An activation of the R-BiP/p62-mediated autophagic degradation pathway may be explained by an impairment of the UPS in myotilinopathy, evidenced by an accumulation of mutant ubiquitin in abnormal fibers [15]. p62 is also involved in chaperone-assisted selective autophagy (CASA), a tension-induced autophagy pathway essential for mechanotransduction in muscle fibers $[39,40]$. The CASA complex comprises the chaperones HSPB8/ Hsp22 and HSPA8/Hsc70, and the co-chaperone BAG3 that were also over-represented in myotilinopathy aggregates. CASA facilitates degradation of damaged Z-disc proteins including filamin $C[39,40]$. We therefore assume that aggregation of $\mathrm{Z}$-disc proteins in myotilinopathy induces an increased expression of CASA components. The finding that abnormal fibers in filaminopathy also show an increased immunoreactivity for CASA proteins [36] suggests that this pathway may be generally important in the pathogenesis of MFM. Another accumulated protein involved in selective autophagosomal protein degradation is NBR1, an autophagic adaptor protein with functions similar to those of p62. Myosin binding protein $\mathrm{H}(\mathrm{MyBPH})$ seems to be involved in autophagosomal membrane maturation processes [41], while the chaperones HSPB1/Hsp27 and $\alpha \mathrm{B}$-crystallin play a role in proteasomal protein degradation [42-44].

Taken together, our proteomic analysis identified several proteins that seem to play a role in the complex regulation of protein degradation in myotilinopathy. We suppose that protein aggregation in abnormal muscle fibers induces increased expression of proteins of the third group which 
interact with or support the degradation of proteins involved in aggregate formation. Since these proteins are potential therapeutic targets, this may be relevant for the development of new treatment strategies. Indeed, it has been shown that e.g. induction of chaperone expression, including proteins that are over-represented in aggregates, efficiently prevented protein aggregation in cell and mouse models of MFM subtypes [45-49]. However, it is unclear if a simple over-expression of proteins involved in degradation processes could be sufficient to eliminate massive protein aggregates. In abnormal fibers impairment of the UPS and autophagy, and factors like oxidative stress may contribute to a resistance of aggregates to degradation $[13,15,32,36,50]$.

Our immunolocalization studies not only confirmed our proteomic findings but surprisingly also revealed different regions of protein accumulation in abnormal fibers. A1 areas correspond to myotilin-positive aggregates. These areas were collected as aggregate samples by our laser microdissection approach and showed an accumulation of the proteins that were identified as over-represented in aggregate samples by mass spectrometric analysis. Abnormal fibers usually displayed a decreased myotilin immunoreactivity outside area $\mathrm{A} 1$. This suggests the assumption that there might be two different kinds of effects of MFM causing MYOT mutations: a toxic gain-of-function leading to myotilin-positive protein aggregates and a loss-offunction caused by a shift in subcellular distribution with a deficiency of myotilin at Z-discs that impairs the integrity of myofibrils. A combination of toxic gain- and loss-offunction has already been discussed in other protein aggregation disorders, e.g. in neurodegenerative diseases $[51,52]$.

The loss-of-function theory in myotilinopathy is supported by identification of abnormal areas A2. These regions showed a decreased myotilin signal but strong accumulation of proteins involved in myofibrillar stabilization, remodeling and repair, such as (co-)chaperones [39, 40,53-55], proteins with a regulatory role in actin dynamics [41, 56-58], and the Z-disc-associated proteins filamin C, N-RAP, Xin and Xirp2 [25, 54, 59-64]. This may be an attempt of abnormal fibers to protect and repair myofibrils that are disturbed due to local myotilin deficiency. In addition, a lack of further proteins may also be relevant as we detected a decreased immunoreactivity of A2 areas for e.g. the Z-disc-associated proteins obscurin, plectin and nestin. A separate collection and analysis of A2 areas would be a promising, but, from a technical point of view, extremely difficult approach at the moment. A main problem is that no specific marker for these areas has been established so far.

A3 areas are primarily located at the periphery of abnormal fibers and characterized by vacuolar changes, absence of intact myofibrils, and increased immunoreactivity for a plethora of proteins including desmin, plectin, nestin, obscurin, sarcolemmal proteins, and several proteins involved in proteasomal and autophagic pathways. We suppose that proteins actually destined for degradation accumulate in these areas. The formation of large vacuoles may be a consequence of an insufficiency and impairment of autophagy. Interestingly, the immunoreactivity for p62 was only slightly increased in A3 areas, whereas NBR1 strongly accumulated. This suggests that the relevance of distinct selective autophagy pathways differs in A1 and A3 areas. The lack of myotilin in A3 areas indicates that it is trapped in A1 areas. A dynamic flux of other overrepresented proteins between different aggregate areas and surrounding sarcoplasm may be possible but this important aspect cannot be assessed by our descriptive immunofluorescence studies. It would be interesting to investigate dynamic processes by e.g. live cell imaging studies but suitable cell culture models of myotilinopathy have not been established so far.

Finally, comparison of data from our proteomic analysis in myotilinopathy with previous findings in filaminopathy and desminopathy $[17,18]$ showed striking similarities especially in respect of Z-discassociated proteins. Desmin, filamin C, myotilin, Xirp2, N-RAP, Xin, $\alpha$ B-crystallin and nestin always ranked among the most abundant over-represented proteins indicating a characteristic basic pattern of aggregate composition in MFM. Differences related to the proportion, ratio and order of proteins allowed the identification of subtype-specific proteomic profiles. The ratio of myotilin to filamin $\mathrm{C}$ in aggregate samples was identified as a highly sensitive and specific marker for myotilinopathy. In addition, the ratio of filamin $\mathrm{C}$ proportions in aggregate and control samples, previously presented as marker to differentiate filaminopathy from desminopathy [18], is also suitable to discern filaminopathy from myotilinopathy. This again demonstrates that proteomic analysis is a valuable tool in the differential diagnosis of MFM. Future studies in other MFM subtypes and further protein aggregate myopathies have to address the issue if other disease entities also display distinct patterns of diagnostic markers.

\section{Ethical Standards}

All procedures performed in studies involving human participants were in accordance with the 1964 Helsinki declaration and its later amendments or comparable ethical standards and with approval of the ethics committee of the Ruhr-University Bochum (\#4368-12).

\section{Conclusions}

Our previous work showed that the combination of laser microdissection with proteomic analysis is a highly sensitive method to decipher the composition of protein 
aggregates in MFM. Our findings in myotilinopathy presented in this work indicate that Z-disc-associated proteins, especially filamin $C$, desmin and their binding partners, are the most abundant components of the pathological aggregates in muscle fibers of myotilinopathy patients. The network of interactions between several of the accumulated proteins suggests that sarcoplasmic aggregates are structured formations. New information concerning over-represented chaperones and proteins involved in the UPS and autophagic pathways are important for understanding pathophysiological aspects and may be relevant for the development of treatment strategies. Our extensive immunolocalization studies not only confirmed the results of our proteomic analysis but also identified different regions of protein accumulation and a lack of myotilin outside the aggregates in abnormal muscle fibers. This raised the important question whether a combination of toxic gain-offunction and loss-of-function of myotilin is present in myotilinopathy. The identification of the ratio of myotilin to filamin $\mathrm{C}$ in aggregates as a highly sensitive and specific diagnostic marker for myotilinopathy underlines that proteomic analysis can be useful in differential diagnosis of myofibrillar myopathies.

\section{Informed consent}

Informed consent was obtained from individual participants included in the study.

\section{Additional files}

\section{Additional file 1: Table S1. Primary antibodies used in double} immunofluorescence studies. (PDF $56 \mathrm{~kb}$ )

Additional file 2: Table S2. Accession number (Swiss-Prot) and names of genes coding for proteins identified as over-represented in aggregate samples in myotilinopathy. (PDF $61 \mathrm{~kb}$ )

Additional file 3: Figure S1. Composition of protein aggregates collected from different muscles in MFM caused by different MYOT mutations. (TIF $1155 \mathrm{~kb}$ )

Additional file 4: Figure S2. H\&E, trichrome and myotilin stain. (TIF $8337 \mathrm{~kb}$ )

Additional file 5: Figure S3. Immunolocalization of myotilin in abnormal fibers. (TIF $4017 \mathrm{~kb}$ )

Additional file 6: Figure S4. Immunolocalization of filamin C and myotilin in a longitudinal muscle section. (TIF $1576 \mathrm{~kb}$ )

Additional file 7: Figure S5. Immunolocalization of additional chaperones. (TIF $5907 \mathrm{~kb}$ )

Additional file 8: Figure S6. Immunofluorescence analyses of control muscle fibers. (TIF $5332 \mathrm{~kb}$ )

Additional file 9: Figure S7. Immunolocalization of 14-3-3 $\gamma$ and lamin A/C. (TIF $3287 \mathrm{~kb}$ )

\section{Competing interests}

The authors declare that they have no competing interests.

\section{Authors' contributions}

$\mathrm{AM}, \mathrm{MV}, \mathrm{KM}$ and RAK conceived and designed the study. MO, SF, JS, BS, MV and RAK were involved in muscle sample acquisition. LGG carried out molecular genetic studies. AS performed laser microdissection and immunofluorescence and histological stainings. AM and VT performed proteomic analysis. JU and ME were involved in bioinformatic analysis of proteomic data. KB and KM supervised proteomic analysis. AM, AKG and RAK evaluated immunofluorescence and histological stainings. AM and RAK interpreted proteomic data and wrote the manuscript. MT, RS, PFMvdV and DOF provided scientific input. All authors were involved in revising the manuscript for intellectual content. All authors read and approved the final manuscript.

\section{Acknowledgements}

The authors thank the patients for participation in this study and Prof. Dr. Gerhard Wiche, Vienna, Austria, for his generous gift of plectin antibodies.

\section{Funding}

This work was supported by the German Research Foundation [Multilocation DFG-Research Units FOR1228 and FOR1352, R.S., D.O.F., K.M., R.A.K.], Ministry of Innovation, Science and Research of the State of North Rhine-Westphalia [P.U.R.E. (Protein Research Unit Ruhr within Europe), K.M., A.M., K.B., M.E., J.U.], and the Heimer Foundation [A.M., A.S., A.K.G., M.V., R.A.K.].

\section{Author details}

'Department of Neurology, Heimer Institute for Muscle Research, University Hospital Bergmannsheil, Ruhr-University Bochum, Buerkle-de-la-Camp-Platz 1, D-44789 Bochum, Germany. ${ }^{2}$ Medizinisches Proteom-Center, Ruhr-University Bochum, D-44801 Bochum, Germany. ${ }^{3}$ Department of Pathology and Neuromuscular Unit, Institute of Neuropathology, IDIBELL-Hospital Universitari de Bellvitge and Centro de Investigación Biomédica en Red de Enfermedades Neurodegenerativas (CIBERNED), Barcelona, Spain. ${ }^{4}$ Department of Neurology, Friedrich-Baur-Institute, Ludwig-Maximilians University of Munich, D-80336 Munich, Germany. ${ }^{5}$ Department of Cytology, Institute of Anatomy, Ruhr-University Bochum, D-44801 Bochum, Germany. ${ }^{6}$ Clinical Neurogenetics, National Institutes of Health, MSC 9404 Bethesda, MD, USA. ${ }^{7}$ Institute of Neuropathology, University Hospital Erlangen, D-91054 Erlangen, Germany. ${ }^{8}$ Institute for Cell Biology, University of Bonn, D-53121 Bonn, Germany.

Received: 23 January 2016 Accepted: 23 January 2016

Published online: 03 February 2016

\section{References}

1. Nakano S, Engel AG, Waclawik AJ, Emslie-Smith AM, Busis NA. Myofibrillar myopathy with abnormal foci of desmin positivity. I. Light and electron microscopy analysis of 10 cases. J Neuropathol Exp Neurol. 1996;55(5):549-62.

2. de Bleecker JL, Engel AG, Ertl BB. Myofibrillar myopathy with abnormal foci of desmin positivity II. Immunocytochemical analysis reveals accumulation of multiple other proteins. J NeuropatholExp Neurol. 1996;55(5):563-77.

3. Selcen D, Ohno K, Engel AG. Myofibrillar myopathy: clinical, morphological and genetic studies in 63 patients. Brain. 2004;127(Pt 2):439-51. doi:10.1093/brain/awh052.

4. Selcen D, Engel AG. Mutations in myotilin cause myofibrillar myopathy. Neurology. 2004;62(8):1363-71

5. Olivé M, Odgerel Z, Martínez A, Poza JJ, Bragado FG, Zabalza RJ, et al. Clinical and myopathological evaluation of early- and late-onset subtypes of myofibrillar myopathy. Neuromuscul Disord. 2011;21(8):533-42. doi:10.1016/j.nmd.2011.05.002.

6. Salmikangas P, Mykkänen OM, Grönholm M, Heiska L, Kere J, Carpén O. Myotilin, a novel sarcomeric protein with two Ig-like domains, is encoded by a candidate gene for limb-girdle muscular dystrophy. Hum Mol Genet. 1999:8(7):1329-36

7. Salmikangas $P$, van der Ven PFM, Lalowski M, Taivainen A, Zhao F, Suila $H$, et al. Myotilin, the limb-girdle muscular dystrophy 1 A (LGMD1A) protein, cross-links actin filaments and controls sarcomere assembly. Hum Mol Genet. 2003;12(2):189-203.

8. van der Ven PF, Wiesner S, Salmikangas P, Auerbach D, Himmel M, Kempa $\mathrm{S}$, et al. Indications for a novel muscular dystrophy pathway. gamma-filamin, the muscle-specific filamin isoform, interacts with myotilin. J Cell Biol. 2000;151(2):235-48. 
9. Gontier Y, Taivainen A, Fontao L, Sonnenberg A, van der Flier A, Carpen O, et al. The Z-disc proteins myotilin and FATZ-1 interact with each other and are connected to the sarcolemma via muscle-specific filamins. J Cell Sci. 2005;118(Pt 16):3739-49. doi:10.1242/jcs.02484.

10. von Nandelstadh P, Ismail M, Gardin C, Suila H, Zara I, Belgrano A, et al. A class III PDZ binding motif in the myotilin and FATZ families binds enigma family proteins: a common link for Z-disc myopathies. Mol Cell Biol. 2009:29(3):822-34. doi:10.1128/MCB.01454-08.

11. Olivé M, Goldfarb LG, Shatunov A, Fischer D, Ferrer I. Myotilinopathy: refining the clinical and myopathological phenotype. Brain. 2005;128(Pt 10):2315-26. doi:10.1093/brain/awh576.

12. Schröder R, Schoser B. Myofibrillar myopathies: a clinical and myopathological guide. Brain Pathol. 2009;19(3):483-92. doi:10.1111/j.1750-3639.2009.00289.x.

13. Olivé M. Extralysosomal protein degradation in myofibrillar myopathies. Brain Pathol. 2009;19(3):507-15. doi:10.1111/j.1750-3639.2009.00288.x.

14. Pénisson-Besnier I, Talvinen K, Dumez C, Vihola A, Dubas F, Fardeau M, et al. Myotilinopathy in a family with late onset myopathy. Neuromuscul Disord. 2006;16(7):427-31. doi:10.1016/j.nmd.2006.04.009.

15. Olivé M, van Leeuwen FW, Janué $A$, Moreno D, Torrejón-Escribano B, Ferrer I. Expression of mutant ubiquitin $(\mathrm{UBB}+1)$ and p62 in myotilinopathies and desminopathies. Neuropathol Appl Neurobiol. 2008;34(1):76-87. doi:10.1111/j.1365-2990.2007.00864.x.

16. Claeys KG, van der Ven PFM, Behin A, Stojkovic T, Eymard B, Dubourg O, et al. Differential involvement of sarcomeric proteins in myofibrillar myopathies: a morphological and immunohistochemical study. Acta Neuropathol. 2009;117(3):293-307. doi:10.1007/s00401-008-0479-7.

17. Kley RA, Maerkens A, Leber $Y$, Theis V, Schreiner A, van der Ven PFM, et al. A combined laser microdissection and mass spectrometry approach reveals new disease relevant proteins accumulating in aggregates of filaminopathy patients. Mol Cell Proteomics. 2013;12(1):215-27. doi:10.1074/mcp.M112.023176.

18. Maerkens A, Kley RA, Olivé M, Theis V, van der Ven PFM, Reimann J, et al. Differential proteomic analysis of abnormal intramyoplasmic aggregates in desminopathy. J Proteomics. 2013;90:14-27. doi:10.1016/j.jprot.2013.04.026.

19. Uszkoreit J, Maerkens A, Perez-Riverol Y, Meyer HE, Marcus K, Stephan C, et al. PIA - An intuitive protein inference engine with a web-based user interface. J Proteome Res. 2015. doi:10.1021/acs.jproteome.5b00121.

20. Fischer D, Clemen CS, Olivé M, Ferrer I, Goudeau B, Roth U, et al. Different early pathogenesis in myotilinopathy compared to primary desminopathy. Neuromuscul Disord. 2006;16(6):361-7. doi:10.1016/j.nmd. 2006.03.007.

21. Nicot A, Lo Verso F, Ratti F, Pilot-Storck F, Streichenberger N, Sandri M, et al. Phosphorylation of NBR1 by GSK3 modulates protein aggregation. Autophagy. 2014;10(6):1036-53. doi:10.4161/auto.28479.

22. Steinert PM, Chou YH, Prahlad V, Parry DA, Marekov LN, Wu KC, et al. A high molecular weight intermediate filament-associated protein in BHK-21 cells is nestin, a type VI intermediate filament protein. Limited co-assembly in vitro to form heteropolymers with type III vimentin and type IV alpha-internexin. J Biol Chem. 1999:274(14):9881-90.

23. Poon E, Howman EV, Newey SE, Davies KE. Association of syncoilin and desmin: linking intermediate filament proteins to the dystrophin-associated protein complex. J Biol Chem. 2002;277(5):3433-9. doi:10.1074/jbc. M105273200.

24. Hijikata T, Murakami T, Ishikawa H, Yorifuji H. Plectin tethers desmin intermediate filaments onto subsarcolemmal dense plaques containing dystrophin and vinculin. Histochem Cell Biol. 2003;119(2):109-23. doi:10. 1007/s00418-003-0496-5.

25. van der Ven PFM, Ehler E, Vakeel P, Eulitz S, Schenk JA, Milting $H_{\text {, }}$ et al. Unusual splicing events result in distinct Xin isoforms that associate differentially with filamin $\mathrm{c}$ and Mena/VASP. Exp Cell Res. 2006;312(11):2154-67. doi:10.1016/j.yexcr.2006.03.015.

26. Oh SW, Pope RK, Smith KP, Crowley JL, Nebl T, Lawrence JB, et al. Archvillin, a muscle-specific isoform of supervillin, is an early expressed component of the costameric membrane skeleton. J Cell Sci. 2003;116(Pt 11):2261-75. doi:10.1242/jcs.00422.

27. Thompson TG, Chan YM, Hack AA, Brosius M, Rajala M, Lidov HG, et al. Filamin 2 (FLN2): A muscle-specific sarcoglycan interacting protein. J Cell Biol. 2000:148(1):115-26.

28. Bennardini F, Wrzosek A, Chiesi M. Alpha B-crystallin in cardiac tissue. Association with actin and desmin filaments. Circ Res. 1992;71(2):288-94.
29. Kato K, Shinohara H, Goto S, Inaguma Y, Morishita R, Asano T. Copurification of small heat shock protein with alpha B crystallin from human skeletal muscle. J Biol Chem. 1992;267(11):7718-25.

30. Zantema A, Verlaan-De Vries M, Maasdam D, Bol S, van der Eb A. Heat shock protein 27 and alpha B-crystallin can form a complex, which dissociates by heat shock. J Biol Chem. 1992;267(18):12936-41.

31. Kley RA, Hellenbroich Y, van der Ven PFM, Fürst DO, Huebner A, Bruchertseifer $V$, et al. Clinical and morphological phenotype of the filamin myopathy: a study of 31 German patients. Brain. 2007;130(Pt 12):3250-64. doi:10.1093/brain/awm271.

32. Ferrer I, Olivé M. Molecular pathology of myofibrillar myopathies. Expert Rev Mol Med. 2008;10, e25. doi:10.1017/S1462399408000793.

33. Rezniczek GA, Konieczny P, Nikolic B, Reipert S, Schneller D, Abrahamsberg $C$, et al. Plectin 1f scaffolding at the sarcolemma of dystrophic (mdx) muscle fibers through multiple interactions with beta-dystroglycan. J Cell Biol. 2007;176(7):965-77. doi:10.1083/jcb.200604179.

34. Zou Y, Zhang R, Sabatelli P, Chu M, Bönnemann CG. Muscle interstitial fibroblasts are the main source of collagen VI synthesis in skeletal muscle: implications for congenital muscular dystrophy types Ullrich and Bethlem. J Neuropathol Exp Neurol. 2008;67(2):144-54. doi:10.1097/nen. ob013e3181634ef7.

35. Ferrer I, Martín B, Castaño JG, Lucas JJ, Moreno D, Olivé M. Proteasomal expression, induction of immunoproteasome subunits, and local MHC class I presentation in myofibrillar myopathy and inclusion body myositis. J Neuropathol Exp Neurol. 2004;63(5):484-98.

36. Kley RA, Serdaroglu-Oflazer P, Leber Y, Odgerel Z, van der Ven PFM, Olivé $M$, et al. Pathophysiology of protein aggregation and extended phenotyping in filaminopathy. Brain. 2012;135(Pt 9):2642-60. doi:10.1093/brain/aws200.

37. Neill T, Schaefer L, lozzo RV. Instructive roles of extracellular matrix on autophagy. Am J Pathol. 2014;184(8):2146-53. doi:10.1016/j.ajpath.2014.05.010.

38. Cha-Molstad H, Sung KS, Hwang J, Kim KA, Yu JE, Yoo YD, et al. Amino-terminal arginylation targets endoplasmic reticulum chaperone BiP for autophagy through p62 binding. Nat Cell Biol. 2015;17(7):917-29. doi:10.1038/ncb3177.

39. Arndt V, Dick N, Tawo R, Dreiseidler M, Wenzel D, Hesse M, et al. Chaperone-assisted selective autophagy is essential for muscle maintenance. Curr Biol. 2010;20(2):143-8. doi:10.1016/j.cub.2009.11.022.

40. Ulbricht A, Eppler FJ, Tapia VE, van der Ven PFM, Hampe N, Hersch N, et al. Cellular mechanotransduction relies on tension-induced and chaperoneassisted autophagy. Curr Biol. 2013;23(5):430-5. doi:10.1016/j.cub.2013.01.064.

41. Mouton J, Loos B, Moolman-Smook JC, Kinnear CJ. Ascribing novel functions to the sarcomeric protein, myosin binding protein $\mathrm{H}(\mathrm{MyBPH})$ in cardiac sarcomere contraction. Exp Cell Res. 2015;331(2):338-51. doi:10.1016/j.yexcr.2014.11.006.

42. Parcellier A, Schmitt E, Gurbuxani S, Seigneurin-Berny D, Pance A, Chantome A et al. HSP27 is a ubiquitin-binding protein involved in I-kappaBalpha proteasomal degradation. Mol Cell Biol. 2003;23(16):5790-802.

43. Lanneau D, Wettstein G, Bonniaud P, Garrido C. Heat shock proteins: cell protection through protein triage. ScientificWorldJournal. 2010;10:1543-52. doi:10.1100/tsw.2010.152.

44. Boelens WC, Croes Y, de Jong WW. Interaction between alphaB-crystallin and the human 205 proteasomal subunit C8/alpha7. Biochim Biophys Acta. 2001:1544(1-2):311-9.

45. Wang X, Klevitsky R, Huang W, Glasford J, Li F, Robbins J. AlphaB-crystallin modulates protein aggregation of abnormal desmin. Circ Res. 2003;93(10): 998-1005. doi:10.1161/01.RES.0000102401.77712.ED.

46. Liu J, Tang M, Mestril R, Wang X. Aberrant protein aggregation is essential for a mutant desmin to impair the proteolytic function of the ubiquitinproteasome system in cardiomyocytes. J Mol Cell Cardiol. 2006:40(4):451-4. doi:10.1016/j.yjmcc.2005.12.011.

47. Chavez Zobel AT, Loranger A, Marceau N, Theriault JR, Lambert H, Landry J. Distinct chaperone mechanisms can delay the formation of aggresomes by the myopathy-causing R120G alphaB-crystallin mutant. Hum Mol Genet. 2003:12(13):1609-20.

48. Sanbe A, Yamauchi J, Miyamoto Y, Fujiwara Y, Murabe M, Tanoue A. Interruption of CryAB-amyloid oligomer formation by HSP22. J Biol Chem. 2007;282(1):555-63. doi:10.1074/jbc.M605481200.

49. Sanbe A, Daicho T, Mizutani R, Endo T, Miyauchi N, Yamauchi J, et al. Protective effect of geranylgeranylacetone via enhancement of HSPB8 induction in desmin-related cardiomyopathy. PLoS One. 2009:4(4), e5351. doi:10.1371/journal.pone.0005351. 
50. Janué A, Olivé M, Ferrer I. Oxidative stress in desminopathies and myotilinopathies: a link between oxidative damage and abnormal protein aggregation. Brain Pathol. 2007;17(4):377-88. doi:10.1111/j.1750-3639.2007.00087.x

51. Winklhofer KF, Tatzelt J, Haass C. The two faces of protein misfolding: gain- and loss-of-function in neurodegenerative diseases. EMBO J. 2008;27(2):336-49. doi:10.1038/sj.emboj.7601930.

52. Lee EB, Lee VM, Trojanowski JQ. Gains or losses: molecular mechanisms of TDP43-mediated neurodegeneration. Nat Rev Neurosci. 2012;13(1):38-50. doi:10.1038/nrn3121.

53. Hishiya A, Kitazawa T, Takayama S. BAG3 and Hsc70 interact with actin capping protein CapZ to maintain myofibrillar integrity under mechanical stress. Circ Res. 2010;107(10):1220-31. doi:10.1161/CIRCRESAHA.110.225649.

54. Crawford GL, Horowits R. Scaffolds and chaperones in myofibril assembly: putting the striations in striated muscle. Biophys Rev. 2011;3(1):25-32. doi:10.1007/s12551-011-0043-x.

55. Golenhofen N, Htun P, Ness W, Koob R, Schaper W, Drenckhahn D. Binding of the stress protein alpha B-crystallin to cardiac myofibrils correlates with the degree of myocardial damage during ischemia/reperfusion in vivo. J Mol Cell Cardiol. 1999;31(3):569-80. doi:10.1006/jmcc.1998.0892.

56. Ogata T, Ueyama T, Isodono K, Tagawa M, Takehara N, Kawashima T, et al. MURC, a muscle-restricted coiled-coil protein that modulates the Rho/ROCK pathway, induces cardiac dysfunction and conduction disturbance. Mol Cell Biol. 2008;28(10):3424-36. doi:10.1128/MCB.02186-07.

57. Gokhin DS, Fowler VM. Tropomodulin capping of actin filaments in striated muscle development and physiology. J Biomed Biotechnol. 2011:2011:103069. doi:10.1155/2011/103069.

58. Hoffmann C, Moreau F, Moes M, Luthold C, Dieterle M, Goretti E, et al. Human muscle LIM protein dimerizes along the actin cytoskeleton and cross-links actin filaments. Mol Cell Biol. 2014;34(16):3053-65. doi:10.1128/ MCB.00651-14.

59. van der Ven PF, Obermann WM, Lemke B, Gautel M, Weber K, Furst DO. Characterization of muscle filamin isoforms suggests a possible role of gamma-filamin/ABP-L in sarcomeric Z-disc formation. Cell Motil Cytoskeleton. 2000;45(2):149-62. doi:10.1002/(SICI)1097-0169(200002)45: 2<149:AID-CM6>3.0.CO;2-G

60. van der Flier A, Sonnenberg A. Structural and functional aspects of filamins. Biochim Biophys Acta. 2001:1538(2-3):99-117.

61. Walter $P$, Ron $D$. The unfolded protein response: from stress pathway to homeostatic regulation. Science. 2011;334(6059):1081-6. doi:10.1126/science. 1209038.

62. Lowe T, Kley RA, van der Ven PFM, Himmel M, Huebner A, Vorgerd M, et al. The pathomechanism of filaminopathy: altered biochemical properties explain the cellular phenotype of a protein aggregation myopathy. Hum Mol Genet. 2007:16(11):1351-8. doi:10.1093/hmg/ddm085.

63. Eulitz S, Sauer F, Pelissier M, Boisguerin P, Molt S, Schuld J, et al. Identification of Xin-repeat proteins as novel ligands of the $\mathrm{SH} 3$ domains of nebulin and nebulette and analysis of their interaction during myofibril formation and remodeling. Mol Biol Cell. 2013;24(20):3215-26. doi:10.1091/mbc.E13-04-0202.

64. Nilsson MI, Nissar AA, Al-Sajee D, Tarnopolsky MA, Parise G, Lach B, et al. Xin is a marker of skeletal muscle damage severity in myopathies. Am J Pathol. 2013;183(6):1703-9. doi:10.1016/j.ajpath.2013.08.010.

\section{Submit your next manuscript to BioMed Central and we will help you at every step:}

- We accept pre-submission inquiries

- Our selector tool helps you to find the most relevant journal

- We provide round the clock customer support

- Convenient online submission

- Thorough peer review

- Inclusion in PubMed and all major indexing services

- Maximum visibility for your research

Submit your manuscript at www.biomedcentral.com/submit
Biomed Central 